\title{
Bioactive Supramolecular Peptide Nanofibers for Regenerative Medicine
}

\author{
Elif Arslan, I. Ceren Garip, Gulcihan Gulseren, Ayse B. Tekinay,* and Mustafa O. Guler*
}

\begin{abstract}
Recent advances in understanding of cell-matrix interactions and the role of the extracellular matrix (ECM) in regulation of cellular behavior have created new perspectives for regenerative medicine. Supramolecular peptide nanofiber systems have been used as synthetic scaffolds in regenerative medicine applications due to their tailorable properties and ability to mimic ECM proteins. Through designed bioactive epitopes, peptide nanofiber systems provide biomolecular recognition sites that can trigger specific interactions with cell surface receptors. The present Review covers structural and biochemical properties of the self-assembled peptide nanofibers for tissue regeneration, and highlights studies that investigate the ability of ECM mimetic peptides to alter cellular behavior including cell adhesion, proliferation, and/or differentiation.
\end{abstract}

\section{Introduction}

Developments in biomaterials science and materials chemistry enable de novo synthesis of bioactive molecules that self-assemble into hierarchical supramolecular structures, eliminating numerous issues associated with the generation of complex networks. With a deeper understanding of cellmaterials and cell-matrix interactions, materials scientists now possess the necessary toolkit to alter cellular processes via engineered biomaterials, which have become indispensable for numerous applications in regenerative medicine. Self-assembled peptide nanofibers comprise one of the major classes of such bioactive materials, and have received substantial attention in the recent decade. A particularly promising application of these peptide networks is the design of artificial extracellular matrices, which display the complex architecture and biochemical properties of their natural counterparts and are crucial for

\footnotetext{
E. Arslan, I. C. Garip, G. Gulseren

Institute of Materials Science and Nanotechnology

National Nanotechnology Research Center (UNAM)

Bilkent University

Ankara 06800, Turkey

Prof. A. B. Tekinay, Prof. M. O. Guler

Institute of Materials Science and Nanotechnology

National Nanotechnology Research Center (UNAM)

Bilkent University

Ankara 06800, Turkey

E-mail: atekinay@unam.bilkent.edu.tr; moguler@unam.bilkent.edu.tr

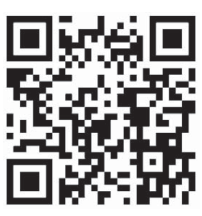

DOI: 10.1002/adhm.201300491 many aspects of tissue regeneration..$^{[1]}$ Peptide nanofibers are particularly advantageous in this capacity, as they undergo a relatively simple self-assembly process, and can be designed to display desirable structural properties. While the biodegradability, oxygen permeability and water storage capacity of hydrogels have led to their extensive clinical use since 1980s, such first examples of hydrogels were bioinert and could not adequately satisfy the strict physiological demands inherent to all human tissues. This problem rendered it necessary to develop biomimetic peptide networks capable of activating specific biological responses and coordinating a wide variety of cellular processes such as cell spreading, differentiation, tissue repair, and regeneration (Figure 1). In Table 1, the list of advantages and drawbacks of peptide nanostructures is summarized.

To guide natural cellular activities, biomaterials should provide a microenvironment similar to that experienced by cells under natural conditions. The native extracellular matrix (ECM) both provides a suitable physical environment and incorporates the necessary set of biochemical and mechanical signals to ensure the normal function of cells, as well as mediating their differentiation, morphogenesis, and homeostasis. ${ }^{[2]}$ Its composition is tissue-specific and heterogeneous, which can be exploited by biomimetic peptides to selectively trigger a particular biological activity, such as cell adhesion, spreading, growth, or differentiation for a specific subset of cells. Integration of a bioactive signal into a given biomaterial will result in the induction of specific cell surface receptors, which can steer the cell population towards a desired behavior. In addition, when cells are in a synthetic environment, their response and eventual fate will be affected by the physical and chemical features of the biomaterial. In both 2D and 3D systems, hydrophobicity, charge, porosity, roughness, and the presence of micro- or nanostructures on the surface, as well as mechanical and physicochemical characteristics, must therefore be considered for bioactive material design. ${ }^{[3,4]}$ In Table 2, the specific features of biomaterials used as scaffold are summarized.

In niches generated by peptide molecules, the order in which epitopes are presented to cells, as well as their intensity, are significant factors in directing cell behavior. ${ }^{[5]}$ Usually, cells adhere to the surface of biomaterials through the adsorbed protein layer. ${ }^{[6]}$ The properties of this protein layer, such as its concentration and distribution, also have fundamental roles of 
regulating biological responses and functionality of the material. ${ }^{[7]}$ Therefore, biomaterials capable of mimicking the natural niche and biochemical cues present in this interface can readily facilitate the attachment of cells. Peptide nanofiber scaffolds engineered with porous structures and high surface to volume ratios provide a suitable spatiotemporal environment for cells to adhere on, and promote the material exchange between the scaffold and the environment. In addition, spatiotemporal signaling patterns can be designed to favor the adhesion, proliferation and/or differentiation of a selected population of cells. Cells continuously receive and process incoming information from the environment and remodel the extracellular structure by degrading it and depositing their own matrix components. This integrin-mediated dynamic and bidirectional interaction between cells and the environment are responsible for directing certain cellular processes to maintain tissue homeostasis. ${ }^{[8]}$

Understanding of specific cell-biomaterials and cell-ECM interactions is paramount to generate functional materials capable of inducing specific responses. Matrix proteins responsible for organizing the cell microenvironment and regulating growth and differentiation are particularly promising candidates for research and their receptor recognition sequences are frequently utilized to generate peptide nanostructures. Peptide chemistry offers a unique opportunity to engineer materials possessing these specific sequences and structures, which may lead to their practical application in regenerative medicine. ECM protein mimics are extensively utilized to guide cell behavior in regenerative medicine, ${ }^{[26]}$ effectively simplifying their models' sophisticated structures without compromising their critical role in maintaining metabolic equilibrium in living systems. In this respect, supramolecular peptide nanofibers have already demonstrated their potential to mimic native ECM with minimal complexity while retaining their desired chemical functions. Among the synthetic regenerative

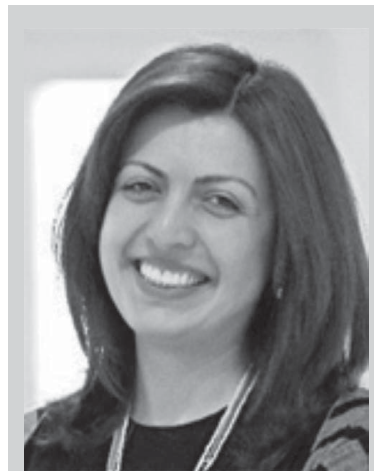

Ayse B. Tekinay is a professor of Materials Science and Nanotechnology at Bilkent University. She received her Ph.D. degree in molecular biology at the Rockefeller University, New York, USA in 2006. After receiving her Ph.D., she continued her post-doctoral studies at the Rockefeller University until 2009. Her research focus is nanobiotechnology, cell-ECM interactions, and use of ECM platforms for tissue regeneration and regenerative medicine.

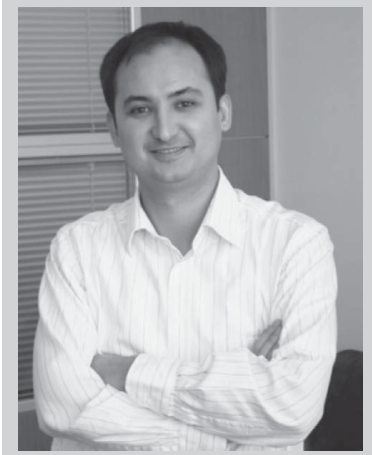

Mustafa O. Guler is a professor of Materials Science and Nanotechnology at Bilkent University. He received his Ph.D. degree in chemistry from Northwestern University in Evanston, IL, USA in 2006. After receiving his Ph.D., he worked at the Institute for Bionanotechnology in Medicine at Northwestern University and Nanotope Inc. in Chicago, IL, USA until 2008. His research is based on discoveries of nanostructures at the interface of chemistry, biology, and materials science.

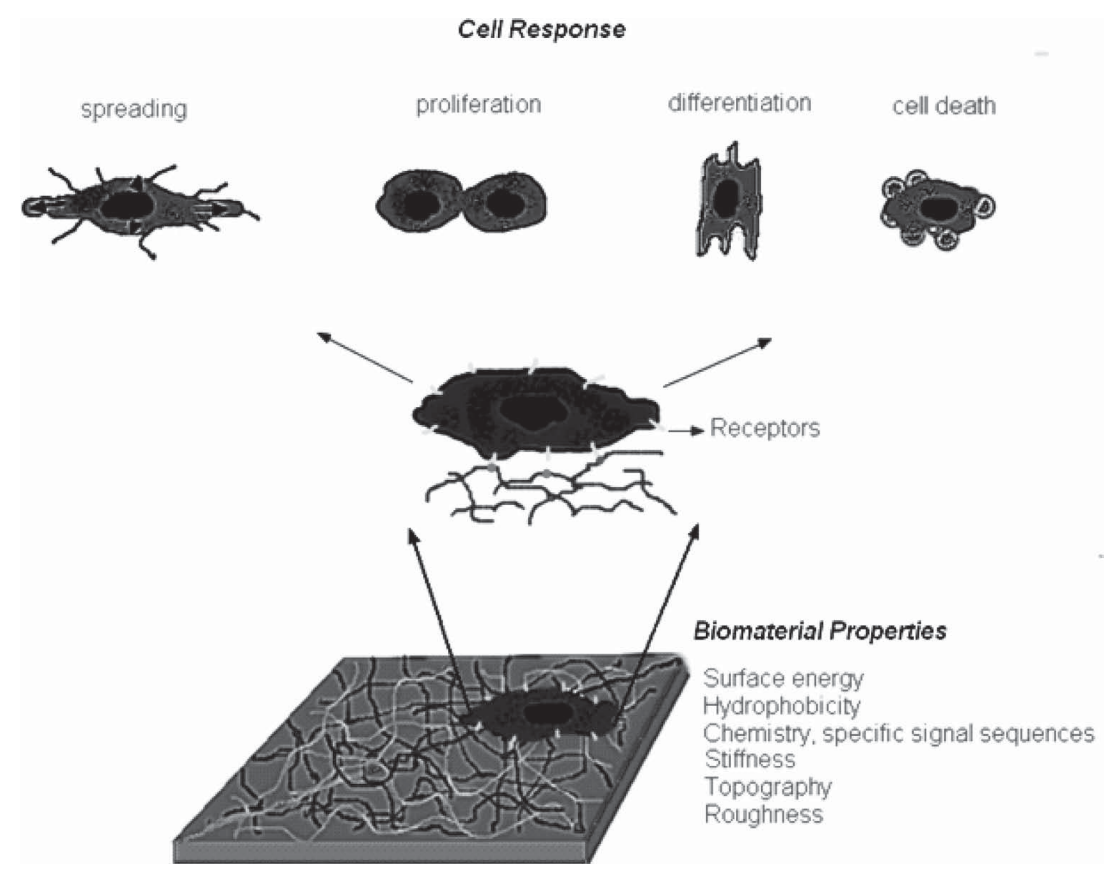

Figure 1. Schematic illustration of biomaterial properties and their possible impact on cell fate. approaches, self-assembled peptide nanofiber systems have a special importance due to their diversity of function and inherent compatibility with biological systems. In this Review, we summarize design and synthesis methods associated with peptide nanofibers, and applications of this important synthetic biomaterials class in regenerative medicine.

\section{Design and Synthesis of Peptide Nanostructures}

Solid-phase peptide synthesis facilitates production of various synthetic peptides. ${ }^{[27]}$ Among synthetic peptide materials, hydrogels are notable for their exceptional structural and functional features. Monomers of synthetically prepared peptide hydrogels are generally classified into mono, di-, and tripeptides, and peptide amphiphiles (PAs), which frequently display complex motifs such as $\alpha$-helices, $\beta$-sheets, coiled-coils, 
Table 1. The list of advantages and drawbacks of peptide-based structures.

\begin{tabular}{lcc}
\hline $\begin{array}{l}\text { Advantages of PAs } \\
\text { Self-assembly, defined sequence design }\end{array}$ & Refs. & \multicolumn{1}{c}{ Disadvantages of PAs } \\
$\begin{array}{l}\text { Bioactivity, biodegradability, oxygen-permeability, high water storage, } \\
\text { high porosity, high surface-to-volume ratio }\end{array}$ & {$[3,83,100,102]$} & Mechanical weakness \\
$\begin{array}{l}\text { Open to modifications } \\
\text { (based on several parameters such as pH and temperature) }\end{array}$ & {$[141,142]$} & Low conductivity \\
$\begin{array}{l}\text { Structural variability and well-defined shapes } \\
\text { (e.g., nanofiber, nanotube, nanoribbon, etc.) }\end{array}$ & {$[147,148]$} \\
$\begin{array}{l}\text { Mild synthesis conditions, low-cost, fast-synthesis } \\
\text { Restricted number of building blocks and limited } \\
\text { sequence size, limited control on final structural size }\end{array}$ & Stability and solubility issues
\end{tabular}

$\beta$-hairpins, and triple helices. In addition, chemical modification of basic peptide motifs can be utilized to provide advanced and additional functions to nanofiber matrices.

\subsection{Self-Assembly Mechanisms}

Amino acids such as phenylalanine and tyrosine are among the smallest hydrogelators studied. ${ }^{[28]}$ Despite their small unit fragments, single amino acid molecules are observed to be efficient, $\mathrm{pH}$ dependent, and thermally reversible hydrogelators. Their small sizes, ease of preparation, and simple structures have made these protected amino acids preferable hydrogelators, and they have become attractive reagents for use in biomedical applications. Monopeptide variants are also frequently utilized for self-assembly, among which the Fmoc-protected amino acids are some of the most commonly studied versions. Fmoc amino acids have been utilized for a variety of other purposes, including external stimuli-triggered hydrogelation. Fmoc-Tyr phosphate provides one of the earliest examples of this phenomenon, as the dephosphorylation of this modified amino acid converts it into an efficient hydrogelator. ${ }^{[29]}$ Fmoc-protected amino acids form hydrogels through $\pi-\pi$ interactions of the Fmoc groups and intermolecular antiparallel hydrogen bonding of the peptide bonds. ${ }^{[30]}$ However, availability of more than 20 standard and non-standard amino acids, with side chains bearing aromatic, hydrophobic, hydrophilic, acidic, and basic moieties, results in large variances of gelation behavior among Fmoc-monopeptides. For example, while Fmoc-Tyr undergoes spontaneous self-assembly in the presence of water, ${ }^{[31]}$ the self-assembly of Fmoc-Phe requires a careful $\mathrm{pH}$ adjustment from basic to neutral acidic. ${ }^{[32]}$ Beside various amino acid side

Table 2. Properties of scaffolds affecting cell interactions.

\begin{tabular}{lc}
\hline Physical and chemical features & Refs. \\
\hline Hydrophobicity & {$[9-11]$} \\
Charge & {$[11,12]$} \\
Porosity & {$[13,14]$} \\
Roughness & {$[9,12]$} \\
Presence of micro- and nanostructures & {$[15-17]$} \\
Mechanical characteristics (elasticity, stiffness etc.) & {$[13,18-20]$} \\
The order and intensity of the epitope & {$[21,22]$} \\
Physicochemical characteristics & {$[23-25]$} \\
\hline
\end{tabular}

chains, critical properties (gelation, functional activity, structure etc.) of peptide hydrogels can be altered not only via endogenous design and but also by external factors such as $\mathrm{pH}$, temperature, and chemical modification. Gelation capability in particular can be augmented with minor modifications. Peptide self-assembly is strongly dependent on the presence of hydrophobic sites or side chains, and can be changed in the absence of a hydrophobic side chain. Electron deficiency is an important parameter to increase the hydrophobicity of the side chain, and electron acceptors such as halogens can be incorporated into the side chain to enhance its hydrophobicity and therefore increase gelation efficiency. Pentafluorination of the phenylalanine side chain, for example, significantly decreases the electron density on the phenyl ring, and the resulting electron deficiency increases the hydrophobicity of the side chain. Substitution is another important factor, especially for aromatic $\pi-\pi$-induced self-assembly: The ortho-substitution in particular attains an electronically favorable structural reorganization that enhances complementary $\pi-\pi$ stacking. ${ }^{[33]}$

Similar to single amino acid derivatives, small molecule hydrogelators also display potential to serve as a general platform for a wide range of applications. These structures are composed of more than one amino acid, potentially in conjunction with a variety of protective and supportive units. As previously mentioned, aromatic interactions play a significant role during the self-assembly process, particularly for the formation of tubular structures. For example, the small molecule hydrogelator diphenylalanine peptide and its modified analogues have been reported to form amyloid-like tubular fibers as a result of their self-assembly process. ${ }^{[35]}$ The hallmark feature of the diphenylalanine hydrogel is its remarkable mechanical rigidity, which exceeds those of hydrogels formed by longer polypeptides. ${ }^{[34]}$ This type of hydrogel is resistant across a broad range of $\mathrm{pH}$ and temperature, and to the presence of some detergents. While self-assembly of this peptide is triggered by aromatic interactions and hydrogen bonds between amide groups, the extraordinary resistance of the hydrogel is principally caused by the directionality of gelation process, provided by $\pi-\pi$ stacking of amino acid groups and their contribution to the free energy of formation.

\subsection{Morphology of the Peptide Aggregates}

The secondary structural motifs are the simplest higher order assembly after small molecular hydrogelators. The $\beta$-sheet, 
which is one of the most thoroughly investigated secondary structures, is composed of two or more $\beta$-strands laterally connected by backbone hydrogen bonds to create a pleated sheet. Fibrous $\beta$-sheet scaffolds are generally formed by mixing two-molar-equivalent solutions of oppositely charged peptides, however, acidic and amphiphilic $\beta$-sheet-forming peptides could also be utilized for $\beta$-sheet formation, even at $\mathrm{pH}$ values much higher than the intrinsic $\mathrm{p} K_{\mathrm{a}}$ of their amino acid side chains. Ionic strength and correlation between the hydrophobic parts and aromatic groups also play a role in $\beta$-sheet assembly. The effect of ionic strength on $\beta$-sheet formation has been investigated by using Ac- $(\mathrm{XKXK})_{2}-\mathrm{Am}$ peptide, ${ }^{[36,37]}$ where charged lysine side chain was utilized to obtain $\mathrm{pH}$ responsiveness. At low $\mathrm{pH}$, peptides remained at monomeric stage due to the repulsion of positive charge on side chain. Lysine residues generated cross- $\beta$ fibril structure with the help of increasing solvent ionic strength as a result of shielded repulsive charge-charge interactions. Aromatic group attachments on the backbones of peptides also display significant effect for self-assembly mechanism. ${ }^{[38]}$ Significance of aromatic group addition is the capability of these groups to lead nanotape and nanoribbon formation apart from nonaromatic peptides.

The $\beta$-hairpin is another secondary structural form and consists of two $\beta$-strands forming a hairpin shape. The $\beta$-hairpins are composed of two antiparallel $\beta$-strands joined by a loop and are commonly recognized components of proteins. Both intermolecular hydrogen bonding and association of hydrophobic faces are the main forces that drive the formation of unique folded conformation of individual hairpins. ${ }^{[39]}$ Due to their high solubility, $\beta$-hairpin peptides also tend to form coiled coils. However, intermolecular folding initiated by external stimuli can induce $\beta$-sheet rich and highly cross-linked $\beta$-hairpin formation. Like $\beta$-sheet formation process, $\beta$-hairpin folding and assembly occurs in response to changes in $\mathrm{pH}$ or ionic strength. Additionally, changes in heat, ${ }^{[39]}$ light, or inclusion of cell culture media to buffered solutions of unfolded peptides result in rigid secondary structure formation. In one study, MAX1 ${ }^{[40]}$ peptide showed $\mathrm{pH}$-sensitive folding characteristics under basic conditions or in the presence of salt, and ionic-strength-driven $\beta$-hairpin monomers were induced to form hydrogel network. In further examples, the distinctive derivatives of MAX peptides (MAX3), ${ }^{[39]}$ showed folding responses against different stimuli including thermal trigger.

Coiled coils are secondary structural motifs constructed by two or more alpha-helices that associate with each other to form dimers, or more multimeric structures. Two, three, or four helices may be present in a single bundle, and these bundles may orient in the same (parallel) or opposite (antiparallel) directions. Each strand of a coiled-coil peptide unit can be considered as a repeated coupling substring of the form a-b-c-d-e-fg sites, where a-b-c-d-e-f-g are the seven different constitutional positions on the coil. The first and fourth position (a and d) are generally nonpolar or hydrophobic amino acids. When the two substrings coil around each other, positions a and d are internalized to stabilize the structure, while remaining positions are exposed on the peptide surface. Leucine-zipper, which has been proven to be important for protein function, ${ }^{[41]}$ is one of the well-studied subtypes of coiled coil constructs, in which the amino acid leucine is predominant at the "d" position of the heptad repeat. These domains may be shorter than 28 amino acids.

Scientists and engineers have also explored the higher order self-assembly type called triple helical assembly. This helical formation has become a promising structural motif for engineering hierarchical and self-assembled constructs mimicking natural tissue scaffolds, which are expected to exhibit specific biological activities. ${ }^{[42]}$ In nature, collagen is a wellknown multi-hierarchical structure that provides the building block for connective tissues. Triple helical peptides with ProHyp-Gly (POG) peptide units can be used to mimic the highlevel structure of collagen. ${ }^{[43]}$ POG fragments undergo selftriggered triple helix formation and these triple helices then pack against one another in a hexagonal and staggered fashion to form nanofibrous structures. Collagen fibers proceed to self-assemble both linearly and laterally to establish collagen mimetic fibers and a hydrogel network. Since the triple helix motif found in collagen is unique and highly specific, and it is a promising candidate of biomimetic strategy for tissue regeneration.

Self-assembling amphiphilic peptides also form various morphologies including fibers, tubes, and vesicles. ${ }^{[4]}$ These peptides contain hydrophobic and hydrophilic residues, which affect assembly of amino acid sequence into specific secondary structures $^{[45]}$ including $\beta$-sheets and $\alpha$-helices. Multiple noncovalent interactions drive the spontaneous self-assembly of individual PA molecules into supramolecular nanostructures under physiological conditions. ${ }^{[46]}$ Such noncovalent interactions are coded in the sequence of PAs and include hydrogen bonding, van der Waals forces, Casimir effect, electrostatic associations, and hydrophobic interactions. Through these intermolecular interactions, especially $\beta$-sheet-forming peptides assemble into 1D nanostructures, which can form 3D fibrous networks. The representative structure of PA molecules composed of one alkyl chain connecting with several amino acid sequences is shown in Figure 2. ${ }^{[46]}$

The hydrophobic alkyl group imitates the nonpolar "tail" region found in fatty acids. This hydrophobic segment can be modulated by using different chain lengths, components, and structures. For example, by using less twisted $\beta$-sheet structures, stiffer materials can be formed. ${ }^{[47]}$ Charged residues can also be incorporated into this region to provide aqueous solubility and regulate hydrogelation. ${ }^{[48]}$ Bioactive domains can be composed of different peptide epitopes according to the purpose of design such as phosphorylated serine, which interact with calcium ions for mineralization of hydroxyapatite (HA). ${ }^{45]}$ This domain presents the bioactivity feature of PAs through specially designed oligo-peptide sequences used as signals for cell adhesion, viability, proliferation, migration, and differentiation. ${ }^{[49]}$ These amphiphilic peptides can form fibrous networks, which are capable of mimicking the dynamic nature of tissue microenvironment. With this fibrous organization and proper composition, they can function cooperatively to achieve the required harmony of flexibility, strength, structural integrity, and complexity of the native extracellular tissue. Due to their biocompatible and biodegradable nature, hydrogels formed by peptide nanofibers have been used to study induction of repair of damaged tissues in regenerative medicine both in vitro and 

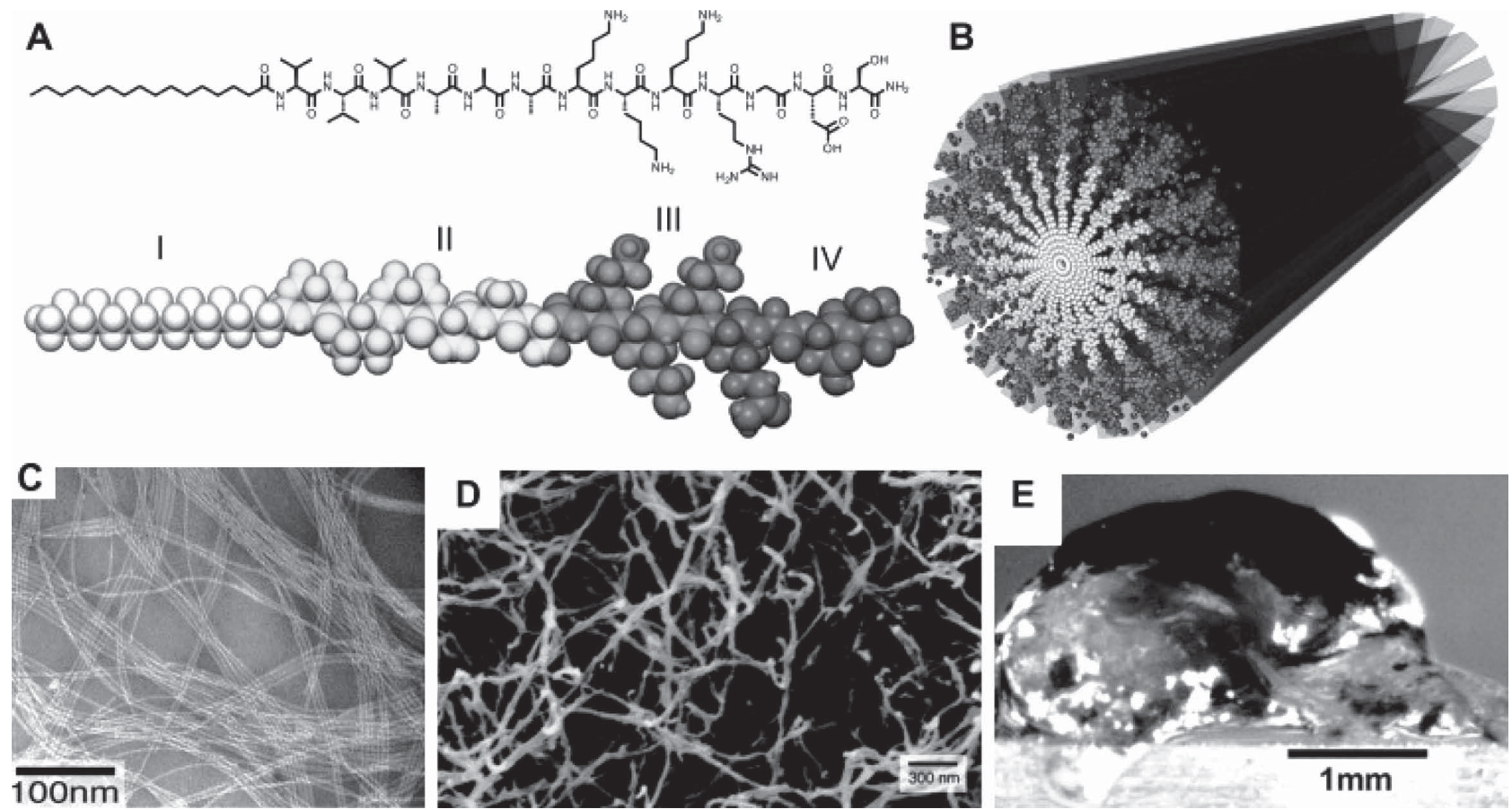

Figure 2. A-I) A hydrophobic alkyl tail, A-II) $\beta$-sheet forming segment, A-III) One or more charged amino acids providing aqueous solubility and further regulate gelation, A-IV) A bioactive epitope. B) Representation of a self-assembled PA nanofiber. C) TEM image of PA nanofibers in aqueous environment. D) SEM image of a PA gel in cell culture media. E) Image of the PA gel formed. Reproduced with permission. ${ }^{[48]}$ Copyright 2002, Elsevier.

in vivo. There are several studies about self-assembled peptide nanofiber systems, ${ }^{[50-55]}$ their characterizations, ${ }^{[56-59]}$ and applications in regenerative medicine. ${ }^{[60-64]}$ Design of bioactive peptide nanostructures depends on the application and tissue type. To induce desired cellular responses such as differentiation and repair, various bioactive sequences can be incorporated into peptide nanostructures. ${ }^{[65]}$ Another example is RADA peptides, containing repeated hydrophilic and hydrophobic amino acid sequences (about $8-16$ residues), which provide both polar and nonpolar features to the peptide. ${ }^{[66-70]}$ Some of these bioactive sequences, which were exploited in different biomedical studies, are shown in Table 3.

\section{Biomedical Applications of Peptide Nanofibers}

\subsection{Bone Regeneration and Biomineralization}

Bone is a highly mineralized, metabolically active and vascularized connective tissue and constitutes the major structural and supportive tissue in the body. Bone defects can occur as a result of trauma, tumors, biochemical disorders, abnormal skeletal development, and severe infections, all of which necessitate urgent medical attention and often require surgical intervention for the reconstruction of the lost bone tissue. ${ }^{[94]}$ However, osseointegration of the implant and the formation of new bone tissue must also occur for complete recovery. Bone formation is initiated with the recruitment and proliferation of osteoprogenitor cells, which later differentiate into osteoblasts to facilitate the production of bone ECM and eventual mineralization of the tissue. ${ }^{[95]}$
Scaffolds for bone regeneration and biomineralization are expected to meet rigid requirements in mechanical tolerance, biocompatibility, and biodegradability. ${ }^{[96]}$ In bone regeneration strategies, an important consideration is the wide diversity of problems associated with this tissue and its unique combination of mechanical, structural, and biological properties. While a large variety of materials have been utilized to overcome such issues, inert and mechanically supportive metals and alloys have so far been widely used as bone implants. However, despite the success of metallic implants and surface modification techniques currently used to accelerate the bone healing process, such surfaces are largely incapable of attracting osteogenic cells in the initial step of osseointegration. Biochemical modifications, such as incorporation of growth factors or ECM proteins to implant surfaces, are therefore critical to induce adequate cell attachment and differentiation during bone repair, especially in conjunction with the optimization of surface roughness and topography. Even though ECM proteins found in bone matrix, such as collagen and fibronectin, are large macromolecules, their integrin recognition parts are short peptide sequences and it is their interaction with integrins and other surface receptors that triggers critical downstream processes such as adhesion and signaling. Thus, PAs with short bioactive peptide sequences have great potential as scaffolds to induce bone tissue growth and biomineralization. Peptides and protein fragments containing RGD, an adhesive sequence found in fibronectin, vitronectin, bone sialoprotein, and osteopontin, ${ }^{[97]}$ were initially used to mimic the function of these proteins. ${ }^{[98]}$ In one of the earlier examples, a supramolecular platform containing a bioactive epitope was designed to trigger the mineralization process. ${ }^{[99]}$ In this 
Table 3. Peptide sequences, their origin and their bioactivity role in tissue regeneration.

\begin{tabular}{|c|c|c|c|}
\hline $\begin{array}{l}\text { Peptide sequence and bioactive peptide } \\
\text { nanofibers }\end{array}$ & Origin & Bioactivity role & Refs. \\
\hline RGDS & $\begin{array}{l}\text { In many ECM proteins, Integrin binding epitope-found } \\
\text { mostly in fibronectin and also ameloblastin (Ambn), }\end{array}$ & $\begin{array}{l}\text { Cell adhesion } \\
\text { Enamel regeneration: cell adhesion to the enamel ECM }\end{array}$ & {$[71-73]$} \\
\hline IKVAV & Laminin & $\begin{array}{c}\text { Cell adhesion, spreading, migration, and neurite } \\
\text { outgrowth }\end{array}$ & {$[74,75]$} \\
\hline YIGSR & Laminin & $\begin{array}{l}\text { Multimeric form inhibits angiogenesis, tumor growth } \\
\text { and experimental metastasis more than the monomeric } \\
\text { form }\end{array}$ & {$[76,77]$} \\
\hline Aligned PA nanofibers & Forming monodomain gel & Directional guidance for regenerating axons & [78] \\
\hline Heparin Binding Peptide amphiphile & $\begin{array}{l}\text { Specifically bind heparan sulphate-like glycosaminogly- } \\
\text { cans (HSGAG) }\end{array}$ & $\begin{array}{l}\text { Binds various signaling proteins through their heparin- } \\
\text { binding domains; such as fibroblast growth factor } 2 \\
\text { (FGF-2), bone morphogenetic protein } 2 \text { (BMP-2) and } \\
\text { vascular endothelial growth factor (VEGF) }\end{array}$ & {$[138]$} \\
\hline PHSRN & $\begin{array}{c}\text { A sequence that binds synergistically with RGD, is } \\
\text { located on an adjacent region of FN and is close enough } \\
\text { to be recognized by the same integrin }\end{array}$ & Cell adhesion & {$[80,139]$} \\
\hline GFOGER and GAOGER & Sequences in Col-IV & Collagen mimetic & {$[79,82]$} \\
\hline Cationic $\alpha$-helical (KLAKLAK) 2 & $\begin{array}{l}\text { Cationic peptides not internalized through cell } \\
\text { membrane }\end{array}$ & Induce cancer cell death by membrane disruption & [140] \\
\hline TGF- $\beta$ binding PA (HSNGLPL) & $\begin{array}{l}\text { Phage display to find a peptide sequence (HSNGLPL) } \\
\text { with a binding affinity to transforming growth factor } \beta 1 \\
\text { (TGF- } \beta 1 \text { ) }\end{array}$ & Articular cartilage regeneration & {$[85]$} \\
\hline LRAP & $\begin{array}{l}\text { Naturally occuring amelogenin splicing isoform, } \\
\text { leucine-rich amelogenin peptide (LRAP), induction of } \\
\text { osteogenesis in various cell types }\end{array}$ & $\begin{array}{l}\text { LRAP activates the canonical Wnt signaling pathway } \\
\text { to induce osteogenic differentiation of mouse ES cells } \\
\text { through the concerted regulation of Wnt agonists and } \\
\text { antagonists }\end{array}$ & {$[86]$} \\
\hline VEGF PA & $\begin{array}{l}\text { VEGF-(vascular endothelial growth factor) angiogenic } \\
\text { factor a mitogen specific for endothelial cells }\end{array}$ & $\begin{array}{l}\text { Recognition of VEGF receptors for induction of endothe- } \\
\text { lial cell proliferation and angiogenesis }\end{array}$ & {$[65]$} \\
\hline $\begin{array}{l}\text { Peptide nucleic acid/peptide amphiphile } \\
\text { conjugate (PNA-PA) }\end{array}$ & $\begin{array}{l}\text { Uncharged PNA backbone providing thermally strong } \\
\text { PNA-DNA and PNA-RNA duplexes and triplexes }\end{array}$ & $\begin{array}{l}\text { Binds to oligonucleotides with high affinity and speci- } \\
\text { ficity after self-assembly into nanostructures. }\end{array}$ & [87] \\
\hline $\mathrm{E}_{3} \mathrm{PA}$ (palmitoyl-A4 G3E3) & $\begin{array}{c}\text { Self-assemble into high aspect ratio cylindrical } \\
\text { nanofibers and encapsulation of drugs by hydrophobic } \\
\text { collapse }\end{array}$ & Antitumor drug encapsulation & [88] \\
\hline $\begin{array}{l}\text { GAG-PA heparan-sulfate-mimicking PA } \\
\text { (HSM-PA) }\end{array}$ & $\begin{array}{l}\text { Heparan sulfate interacts with many ECM molecules } \\
\text { and growth factors }\end{array}$ & $\begin{array}{l}\text { Promoting neurite outgrowth, promote angiogenesis } \\
\text { without the need for addition of exogenous heparin or } \\
\text { growth factors }\end{array}$ & [89] \\
\hline KRSR & Binds to transmembrane proteoglycans & $\begin{array}{l}\text { Selectively increase osteoblast adhesion when function- } \\
\text { alized with other bio-adhesive moieties }\end{array}$ & {$[84,90]$} \\
\hline DGEA & Collagen type I adhesive peptide sequence & Specific binding for osteoblasts via alpha2-beta1 integrin & {$[84]$} \\
\hline YIGSR-IKVAV hybrid form & Laminin & Supporting neuronal survival and morphogenesis & {$[76]$} \\
\hline Dexamethasone-releasing PA & $\begin{array}{l}\text { Providing covalent attachment via a hydrazone and } \\
\text { controlling drug release }\end{array}$ & Controlled drug release & [91] \\
\hline Carbon monoxide-releasing PA & $\begin{array}{c}\mathrm{Ru}(\mathrm{CO})_{3} \mathrm{Clr} \text { (glycinate) motif similar to CORM-3 } \\
\text { (spontaneously releases } \mathrm{CO} \text { ) }\end{array}$ & $\begin{array}{l}\text { Prolong CO release, and localized therapeutic CO } \\
\text { delivery for oxidatively stressed cardiomyocytes }\end{array}$ & [92] \\
\hline RADA (Ac-RADARADARADARADA-Am) & $\begin{array}{l}\text { Originally designed as ionic self-complementary oligo- } \\
\text { peptides, resembling RGD motif }\end{array}$ & $\begin{array}{l}\text { Cell adhesion neurite outgrowth and neuron } \\
\text { differentiation }\end{array}$ & {$[68,93]$} \\
\hline
\end{tabular}

system, the phosphoserine residue, which is characteristic of proteins found in mineralized tissues, was utilized to elicit the deposition of HA, and it has been shown that the $\mathrm{pH}$-induced, self-assembled, phosphoserine-bearing PA matrix was a useful template for the formation of HA crystals. ${ }^{[100]}$ Another study focused on the effect of PAs on tooth regeneration, using a 3D nanofiber scaffold formed by PAs bearing RGD epitopes. ${ }^{[101]}$ Ameloblast-like cells (line LS8) and primary enamel organ epithelial (EOE) cells were cultured on the biomimetic scaffold, and showed enhanced proliferation and expression of amelogenin, an important protein in the development of enamel. ${ }^{[101]}$ In the in vivo part of this study, the RGD-PA hydrogel was 
A.

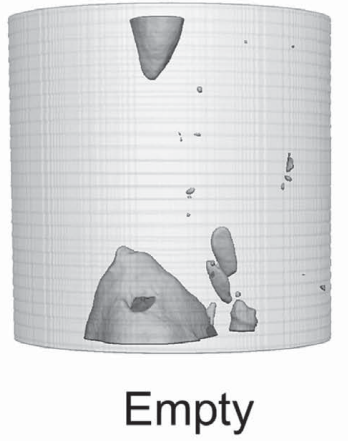

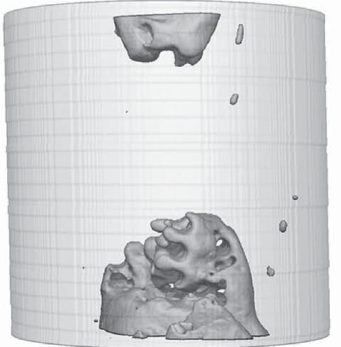

PCL

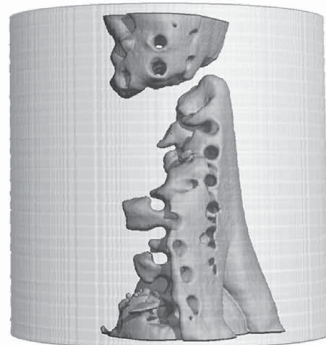

GFOGER

B.

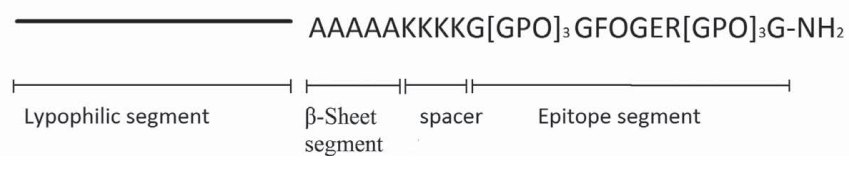

Figure 3. A) Three-dimensional micro-CT representative images of GFOGER-coated scaffolds after 12 weeks. Reproduced with permission. ${ }^{\text {[82] }}$ Copyright 2010, Elsevier. B) Structure of a collagen mimetic peptide with the bioactive epitope GFOGER. Reproduced with permission. ${ }^{[106]}$ Copyright 2011, American Chemical Society.

injected to mouse incisors and found to encourage the proliferation of EOE cells in the site of injection, as well as their differentiation to ameloblasts, suggesting that RGD-PA nanofibers might be able to participate in integrin-mediated cellmatrix adhesion interactions and to introduce the necessary signals for enamel formation.

Peptide amphiphile nanofibers are also used to functionalize implant materials to be used as bone plates, stents, and artificial joints. ${ }^{[5,102,103]}$ For this purpose, the cellular adhesion sequence RGDS was used to covalently functionalize NiTi surfaces, and the bioactivity of the PA system was evaluated in terms of cellular adhesion and proliferation of osteoblasts and endothelial cells. ${ }^{[104]}$ These PA nanofibers were shown to facilitate cell adhesion and enhance the proliferation of cells within $7 \mathrm{~d}$. The ability of the self-assembled peptide nanostructured hydrogels to promote bone regeneration was investigated in another study, where the phospho-serinecontaining peptide (S(P)-PA), and the RGD epitope-bearing peptide (RGDS-PA) were tested in a rat femoral critical-size defect model, and were shown to support bone regeneration in 4 weeks by histology analysis and micro-computed tomography. ${ }^{[105]}$

The GFOGER peptide sequence is another important signal, which was derived from collagen and is known to bind integrin $\alpha 2 \beta 1$, a key protein in osteogenesis. Recognition of this sequence occurs in a conformation-dependent manner, which is unusual for collagen-derived sequences. ${ }^{[106]}$ This signal sequence has been used to induce osteoprogenitor cells to differentiate into osteoblasts, and Wojtowicz et al. have shown that polycaprolactone scaffolds coated with GFOGER promote bone formation in critical-sized segmental defects in rats. In particular, passively adsorbed GFOGER coatings significantly accelerated and increased bone formation in non-healing femoral defects compared to uncoated scaffolds and empty defects. ${ }^{[82]}$ Three-dimensional micro-CT reconstruction images also demonstrated that defects treated with GFOGER-coated scaffolds were almost entirely repaired after 12 weeks (Figure 3).

Collagen I is another important component of the bone ECM, and bioactive sequences derived from this protein are prime candidates for induction of bone tissue regeneration. DGEA, a signal sequence derived from the $\alpha 1$ helix of collagen I, has been investigated for its osteoinductive potential, and DGEA-coated HA disks were found to upregulate the differentiation of mesenchymal stem cells into osteoblasts. ${ }^{[107]}$ However, another study has reported a lack of adhesion by rat calvarial osteoblasts onto a CGGDGEAG sequence. ${ }^{[108]}$

Anderson et al. investigated the osteoinductive potentials of DGEA-PA, RGDS-PA, and S-PA in combination with a conditional medium. Histochemical staining and PCR results showed that the RGDS- and DGEA-PA functionalized surfaces enhanced osteogenic differentiation, compared with S-PAcoated and TCP control surfaces. ${ }^{[109]}$

The KRSR peptide, found in heparin-binding proteins of the ECM, promotes selective adhesion of osteoblasts while inhibiting the adhesion of fibroblasts. ${ }^{[05,110]}$ Previously, titanium alloy (Ti6Al4V) surface was functionalized with KRSR-PA and DOPA-conjugated PA, and combination of these two biomimetic sequences induced osteogenic differentiation. ${ }^{[103]}$ Immobilization of bioactive nanofibers onto Ti6Al4V was mediated by DopaPA (Figure 4) and the osteoconductive interface led to the induction of osteogenesis of osteoblast-like cells (Saos2 cells), which and inhibition of fibroblast adhesion and viability.[103] Alkaline phosphatase activity assay and Alizarin Red S staining results clearly demonstrated osteogenic differentiation of Saos2 cells (Figure 5).

Bone morphogenetic protein-2 (BMP-2) is an important factor regulating bone differentiation. Lee et al. generated an osteopromotive nanofiber network incorporating BMP receptorbinding sequences and calcium ions. ${ }^{[11]}$ Calcein staining and 


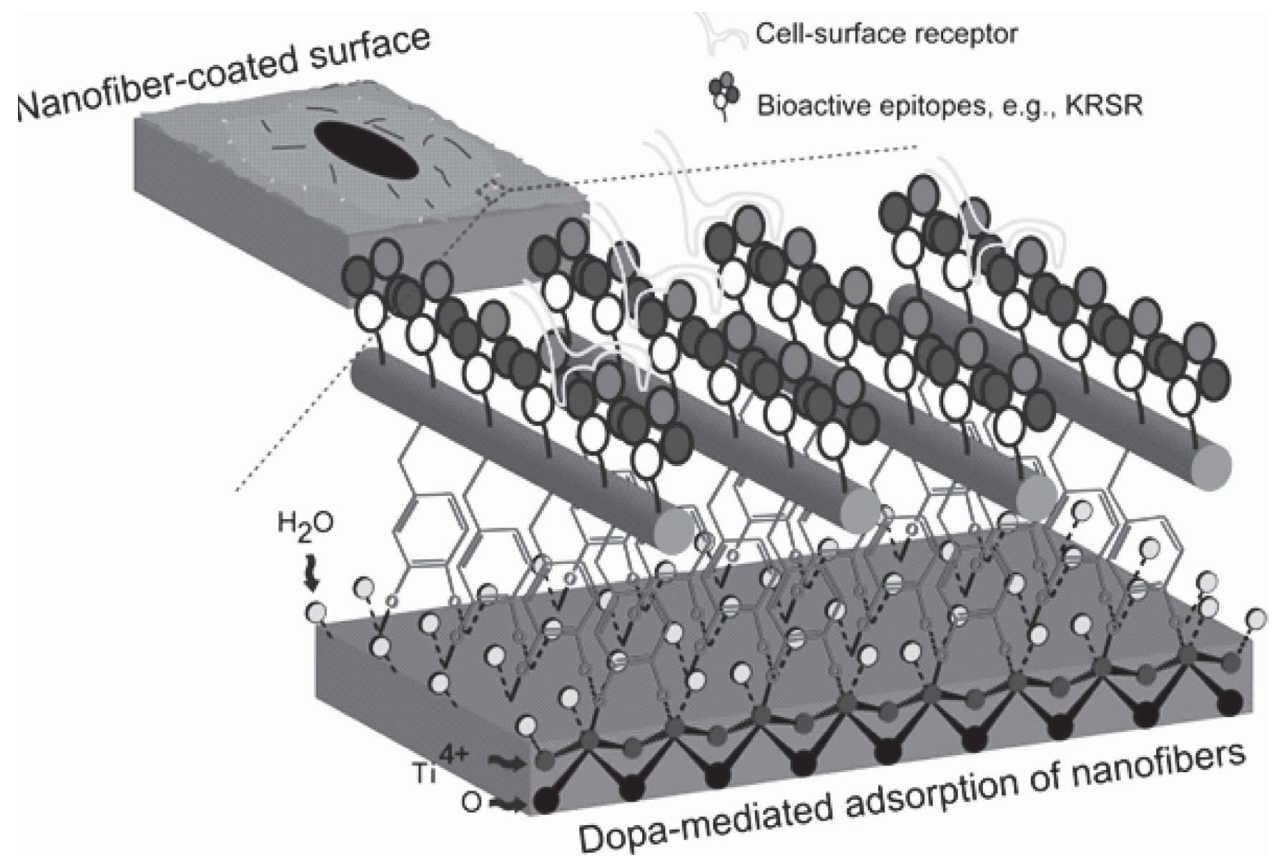

Figure 4. Schematic illustration of immobilization strategy on titanium surface based on the self-assembly of the KRSR-PA and Dopa-PA. Reproduced with permission. ${ }^{[103]}$ Copyright 2012, Royal Society of Chemistry.

ALP activity measurements demonstrated that human bone marrow stromal cells (hBMSCs) grown on BMP-mimetic hydrogels displayed osteogenic differentiation. It was also reported that self-assembled BMP receptor-binding peptides (termed osteopromotive domains, OPD) with DWIVA and $\mathrm{A}_{4} \mathrm{G}_{3}$ EDWIVA sequences were capable of maintaining osteogenic activity (Figure 6).

Recently, bone regeneration was examined through BMP-2 signaling with heparin-binding fibronectin-like PA nanofibers. ${ }^{[112]}$ BMP-2, heparan sulfate, and fibronectin fibers were all able to interact within the matrix, as all three molecules

A)

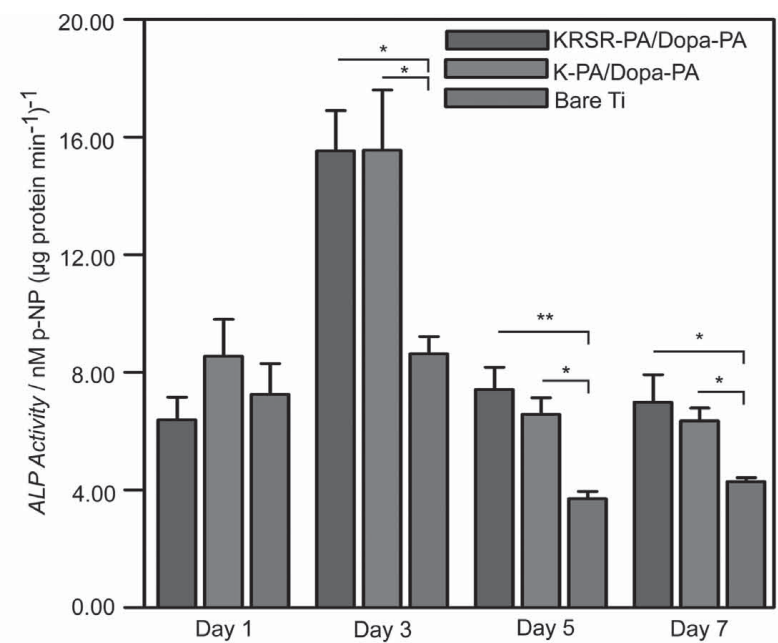

could infiltrate within the pores of a collagen scaffold. This combination was hypothesized to recreate the 3D configuration of receptor-ligand interactions due to the synergistic effect of heparan sulfate-BMP-2 and heparan sulfate-fibronectin interactions on receptor-ligand binding (Figure 7). The ability of this complex matrix to induce bone regeneration was demonstrated on a rat femoral critical-size defect model, where less than $10 \%$ of the required dose of BMP-2 was sufficient to repair the tissue damage when the biomimetic supramolecular system was used within the conventional collagen matrix (Figure 8).

B)
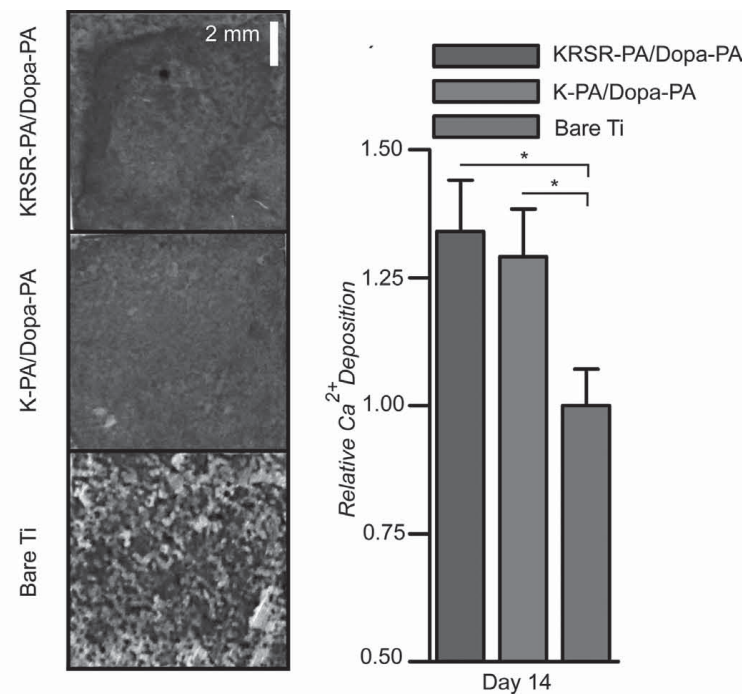

Figure 5. A) ALP activity of Saos2 cells on functionalized surfaces. B) Relative calcium deposition on the matrix. Reproduced with permission. ${ }^{103]}$ Copyright 2012, The Royal Society of Chemistry. 

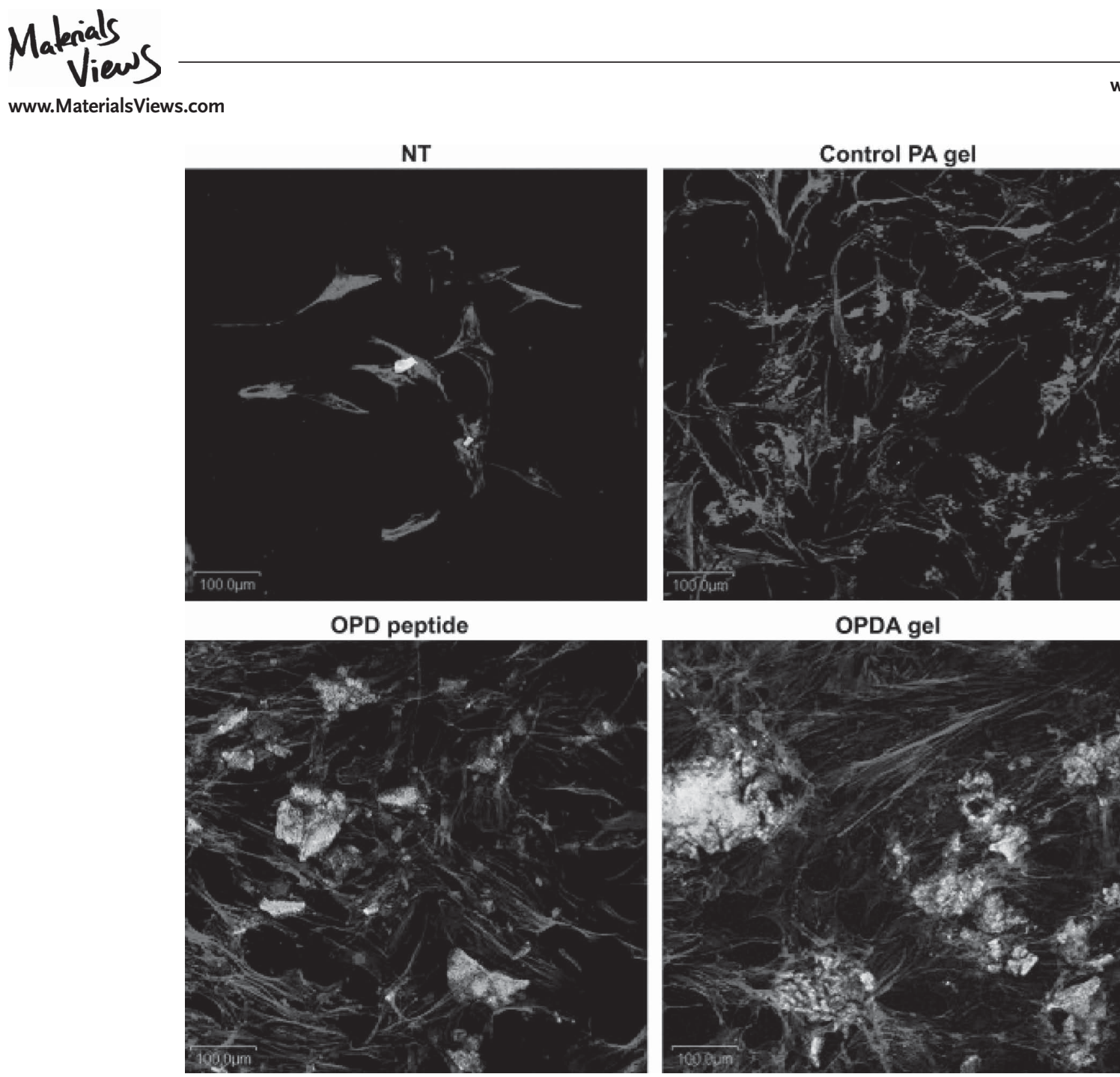

Figure 6. Confocal images of the calcein-stained hBMSCs cultured on either a self-assembled OPDA network or a control PA gel. Reproduced with permission. ${ }^{[11]}$ Copyright 2009, Elsevier.

\subsection{Neural Tissue Regeneration with Peptide Nanofibers}

Inhibition of axonal regeneration and the inability of damaged neurons to form new functional connections are the main problems associated with nervous system repair. Functional recovery after injury and repair depends on a multitude of intrinsic and extrinsic factors, including neurotrophins, neuropoietic cytokines, insulin-like growth factors (IGFs), and glial cell-line-derived neurotrophic factors (GDNFs). ${ }^{[13]}$ While advanced microsurgery techniques may result in an improved outcome, functional recovery is nonetheless poor due to the occurrence of motor and sensory deficits. ${ }^{[114]}$ Poor
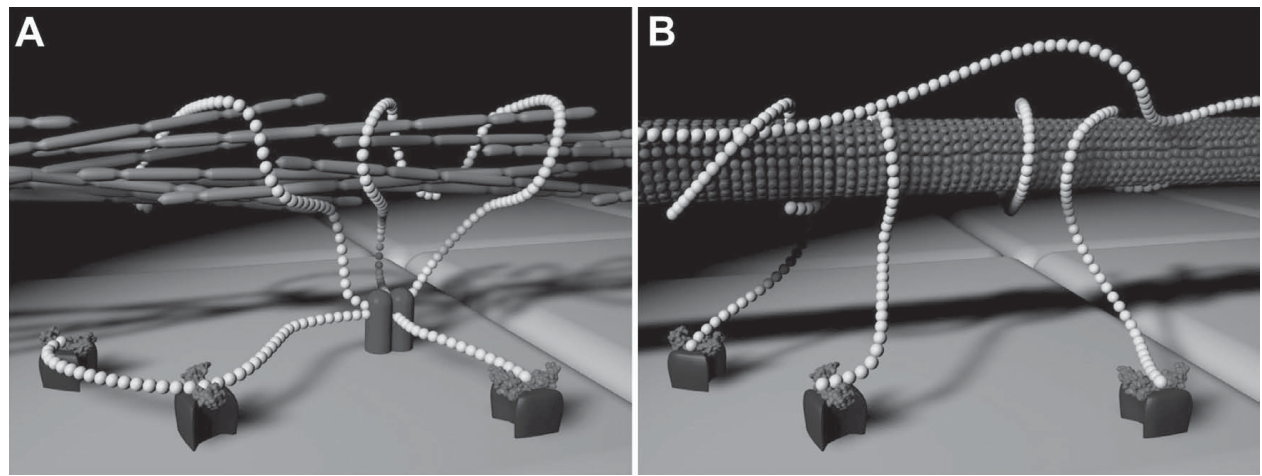

Figure 7. A) Representative illustration of extracellular matrix components involved in ligand-receptor interactions through BMP-2 signaling. B) Representative illustration of fibronectin mimetic nanofiber displaying sulfated polysaccharide strands on its surface, which can localize BMP-2 to facilitate receptor-ligand interactions. Reproduced with permission. [112] Copyright 2013, Elsevier. 
A

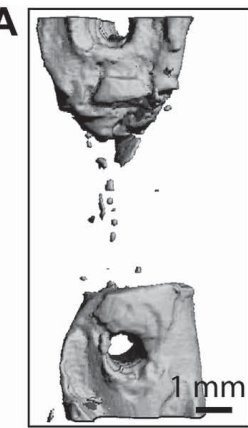

Empty

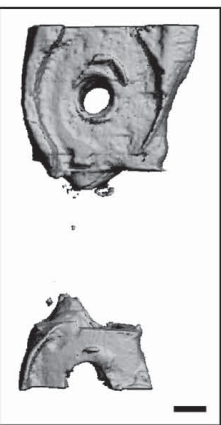

Coll

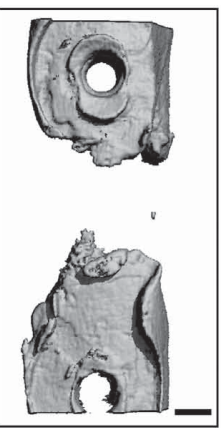

Coll+HBPA+HS

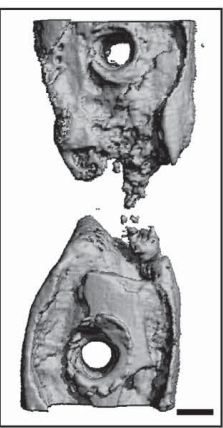

Coll+BMP-2

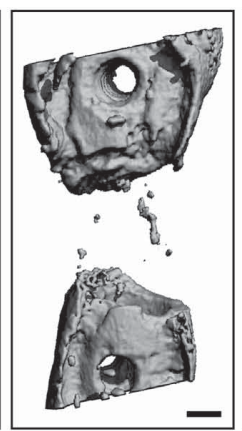

Coll+HS+BMP-2

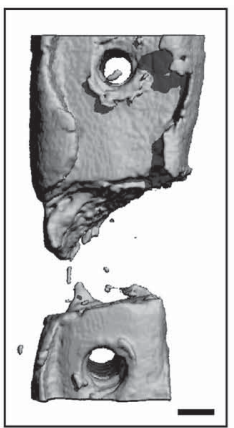

Coll+HBPA

www.MaterialsViews.com

Figure 8. Micro-computed tomography results of femur reconstructions for various treatment groups. HBPA: Heparin Binding PA, HS: Heparan Sulfate. Reproduced with permission. ${ }^{[12]}$ Copyright 2013, Elsevier.

regenerative capacity was previously reported to be associated with the existence of anti-growth and anti-adhesion signals in the neural ECM, ${ }^{[68]}$ suggesting that the negation of inhibitory signals may result in repair and regeneration of neural tissue, especially if inducers of proliferation and regeneration are also present at the damage site. ${ }^{[115]}$ Therefore, generation of a mechanically and chemically suitable environment by means of a biomimetic scaffold may prevent the growth of scar tissue while promoting neuronal outgrowth. Bioactive self-assembled peptide scaffolds with cell-specific signals are promising tools for generating functional microenvironments for neural regeneration, and several studies have already been conducted on the applications of self-assembled peptide nanofibers in neural tissue repair and regeneration. Holmes et al. used RADA16-I as a scaffold to enhance the neural differentiation of PC12 cells, and reported extensive primary neuron neurite outgrowth in the presence this peptide. In addition, they observed a "permissive" substrate effect of the peptide scaffold for primary

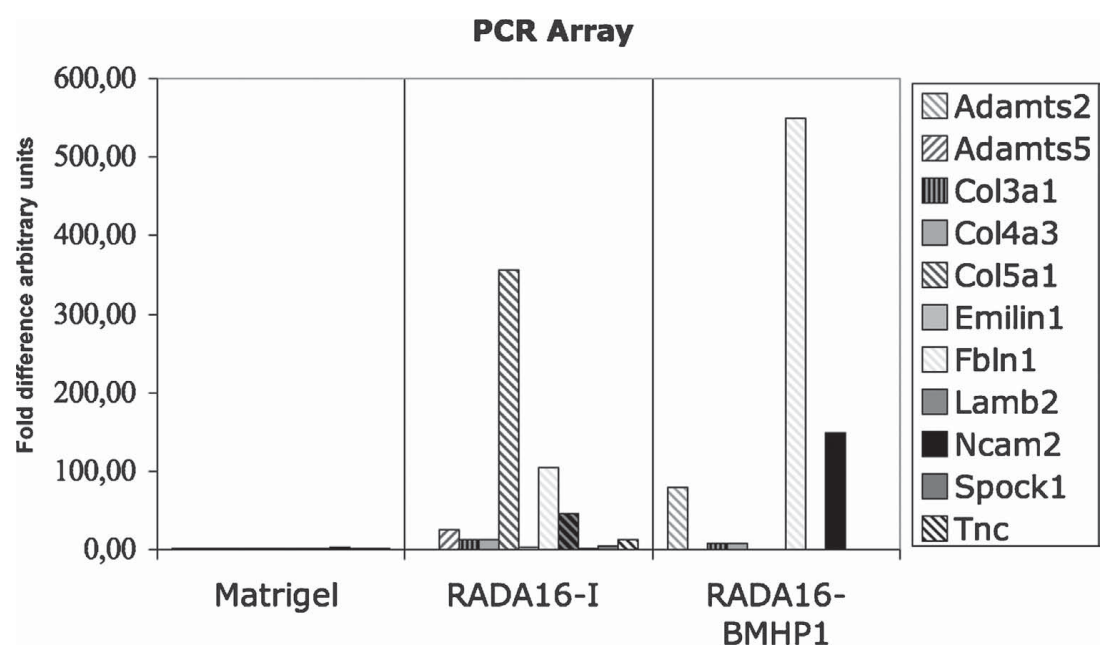

Figure 9. Gene expression levels of the cells cultured on different peptide scaffolds. Adamts 2-5: disintegrin-like and metalloprotease (reprolysin type) with thrombospondin type 1 motif, 2 or 5; Col3a1: Procollagen, type III, alpha 1; Col4a3: Procollagen, type IV, alpha 3; Col5a1: Procollagen, type V, alpha 1; Col5a1: Procollagen, type V, alpha 1; Emilin1: Elastin microfibril interfacer 1; Fbln1: Fibulin 1; Lamb2: Laminin, beta 2; Ncam2: Neural cell adhesion molecule 2; Spock1: Sparc/osteonectin, cwcv and kazal-like domains; Tnc: Tenascin C. Reproduced with permission. ${ }^{[11]}$ Copyright 2006, PLOS. neuronal synapse formation in vitro. ${ }^{[68]}$ Another work utilized a 3D network of PAs containing IKVAV peptide sequence, which was derived from the vital ECM component and neurite growth inducer, laminin. These nanofibers assembled into hydrogels in aqueous environment and were found to facilitate the rapid differentiation of murine neuronal progenitor cells into neurons (NPC). IKVAV containing peptide nanofibers could also inhibit astrocyte differentiation, which is likely to hinder glial scar formation and promote neural regeneration. Another important conclusion was that the ability of these peptides to induce selective and rapid differentiation of progenitor cells depended on the density of the bioactive epitope present in the nanofibers. ${ }^{[116]}$ In a 3D encapsulation study, Gelain et al. designed a self-assembled peptide nanofiber (RADA16) functionalized with a variety of motifs known to play roles in neural adhesion and differentiation. These motifs were based on RGD (RGDS from fibronectin and PRGDSGYRGDS from collagen VI, both for neuron sprouting), laminin (YIGSR, IKVAV, and PDSGR, for neurite outgrowth in vitro and in vivo), a bioregulatory mediator domain from a myelopeptide (GFLGPT, for bone marrow and peripheral blood cell differentiation) and bone marrow homing peptides (SKPPGTSS (BMHP1) and PFSSTKT (BMHP2), for cell survival and cell differentiation). Gene expression analyses of genes, which are important in neural tissue formation, such as fubilin-1, demonstrated that the bioactive motifs were significantly more capable inducers of differentiation of neural cells compared with the Matrigel (Figure 9). ${ }^{71]}$

Peptide scaffolds were also effective in mitigating neural damage, as their presence enhanced the recovery of disrupted tissue and decreased the sequela. In this way, Ellis-Behnke et al. described a permissive microenvironment formed by self-assembled peptide scaffolds (RADA16-I) for in vivo neural regeneration. Their peptides could provide significant axonal growth, facilitating the partial recovery of the optic tract and restoring functional vision in adult animals following a branchium 


\section{Descending Corticospinal Motor Axons}

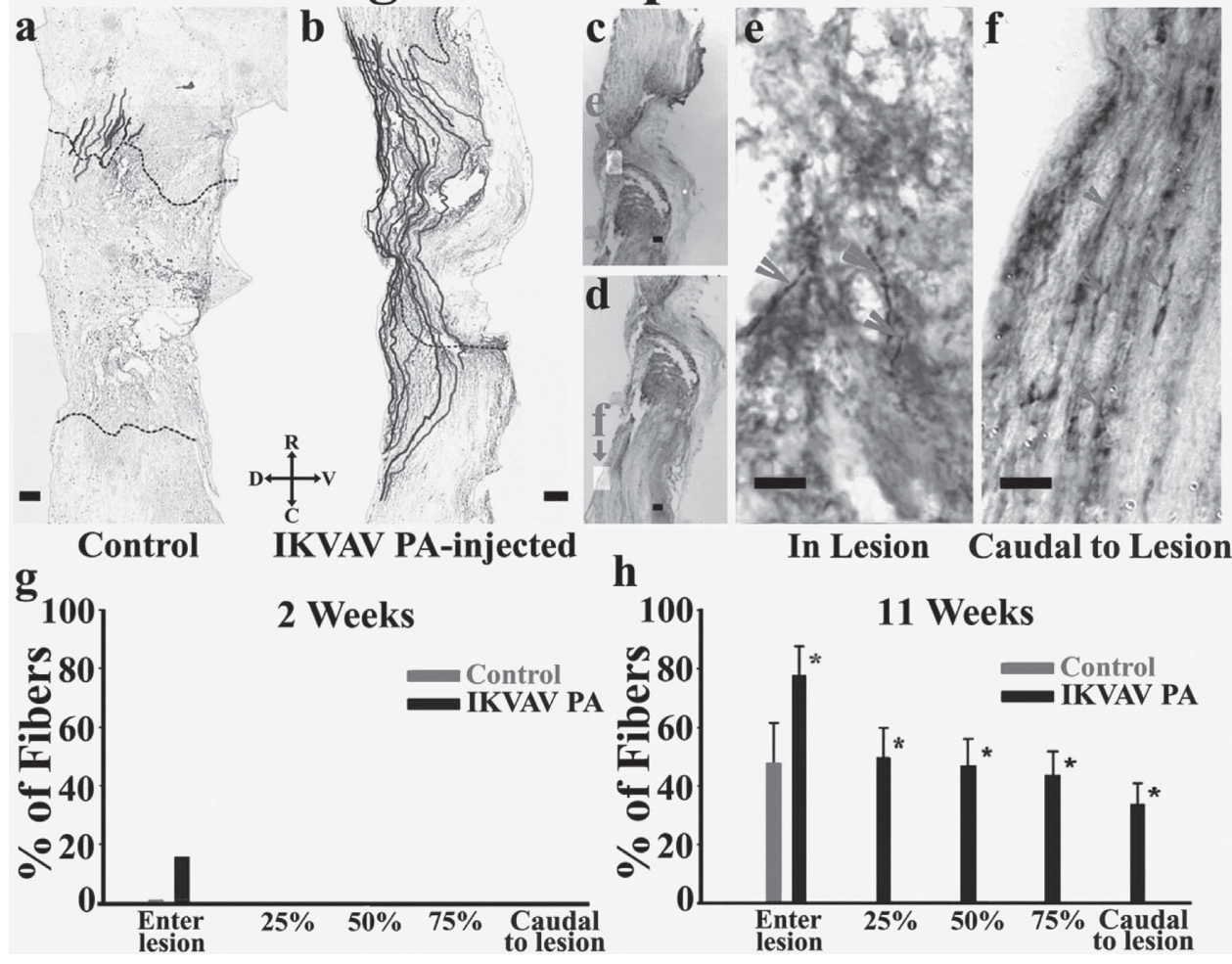

Figure 10. Enhancement in the regeneration of sensory axons within IKVAV PA. a,b) Neurolucida tracings of BDA-labeled descending motor fibers a) Vehicle-injected animals and b) IKVAV PA-injected animals. The dotted lines mark the borders of the lesion. c-f) Bright-field images of BDA-labeled tracts $c, e$ ) in lesion and $d, f$ ) caudal to lesion used for Neurolucida tracings in an IKVAV PA-injected spinal cord (a,b). g,h) Graphics show the amount of labeled corticospinal axon penetration into the lesion. R, Rostral; C, caudal; D, dorsal; V, ventral. Scale bars: a-d) 100 um; e-f) 25 um. Reproduced with permission. ${ }^{[75]}$ Copyright 2008, Society for Neuroscience.

transaction. ${ }^{[117]}$ In another study, IKVAV-containing peptide nanofibers were shown to augment motor axon and sensory axon regeneration after spinal cord injury in vivo (Figure 10). ${ }^{[75]}$

Zou et al. designed another peptide nanofiber system, RADAFGL, by incorporating the FGL motif (EVYVVAENQQGKSKA, originally from Neural Cell Adhesion Molecule) into the peptide RADA16. Their peptide system was shown to be biocompatible, and displayed a permissive effect on neurite sprouting in rat dorsal ganglion neurons. ${ }^{[118]}$ Zou et al. also designed self-assembled nanostructures comprising functionalized peptides with four, two, or no glycine-spacers between the RADA16-I sequence and a motif (PESSTKT) from BMHP1. They demonstrated that the presence and length of glycine spacer significantly alters functionality, and proposed that longer glycine spacers increase the effectiveness of the peptide sequence and enhance the viability and differentiation of neural stem cells in vitro. ${ }^{[119]}$

In addition to regeneration of the central nervous system, neural tissue engineering has also focused extensively on supporting the recovery of peripheral nervous system following an injury. Peptide nanofibers are also promising scaffolds for such applications, and have been investigated by Angeloni et al. in their capacity as in vivo protein delivery vehicles. In their study, aligned PA gels incorporating the sonic hedgehog protein $(\mathrm{SHH})$ have been utilized for regeneration of the cavernous nerve $(\mathrm{CN})$, which enervates penis. SHH plays an important role in maintaining the structural integrity of the $\mathrm{CN}$, as well as facilitating its regeneration after damage. Aligned PA nanofibers (Figure 11) can ideally present $\mathrm{SHH}$, which is an essential protein, while providing directional guidance to regenerating axons. SHH-PA fibers placed on the $\mathrm{CN}$ were found to be capable of maintaining the integrity of myelinated fibers and facilitating the development of axonal sprouts after 4 weeks, though the complete regeneration of the $\mathrm{CN}$ requires a longer period of time. Both qualitative and quantitative results suggested that $\mathrm{SHH}$ delivery with aligned PAs had a great potential for the $\mathrm{CN}$ regeneration (Figure 12). Moreover, PA bundle treatment suppressed penile apoptosis and yielded a $58 \%$ improvement in erectile function in a shorter time period. ${ }^{[78]}$

In a recent study, Sur et al. described a hybrid matrix composed of neuro-active PA and collagen. Combining the beneficial mechanical properties of collagen and the bioactivity of laminin-derived PA (IKVAV-PA and YIGSR-PA), their system could easily be adjusted to present different epitope densities, and displayed a beneficial effect on neuronal viability and morphogenesis (Figure 13). ${ }^{\text {76] }}$

A peptide nanofiber system composed of heparan sulfate mimetic and laminin-derived epitopes was previously designed. The two bioactive components were presented on the nanofiber scaffold, providing neural ECM analogues that 


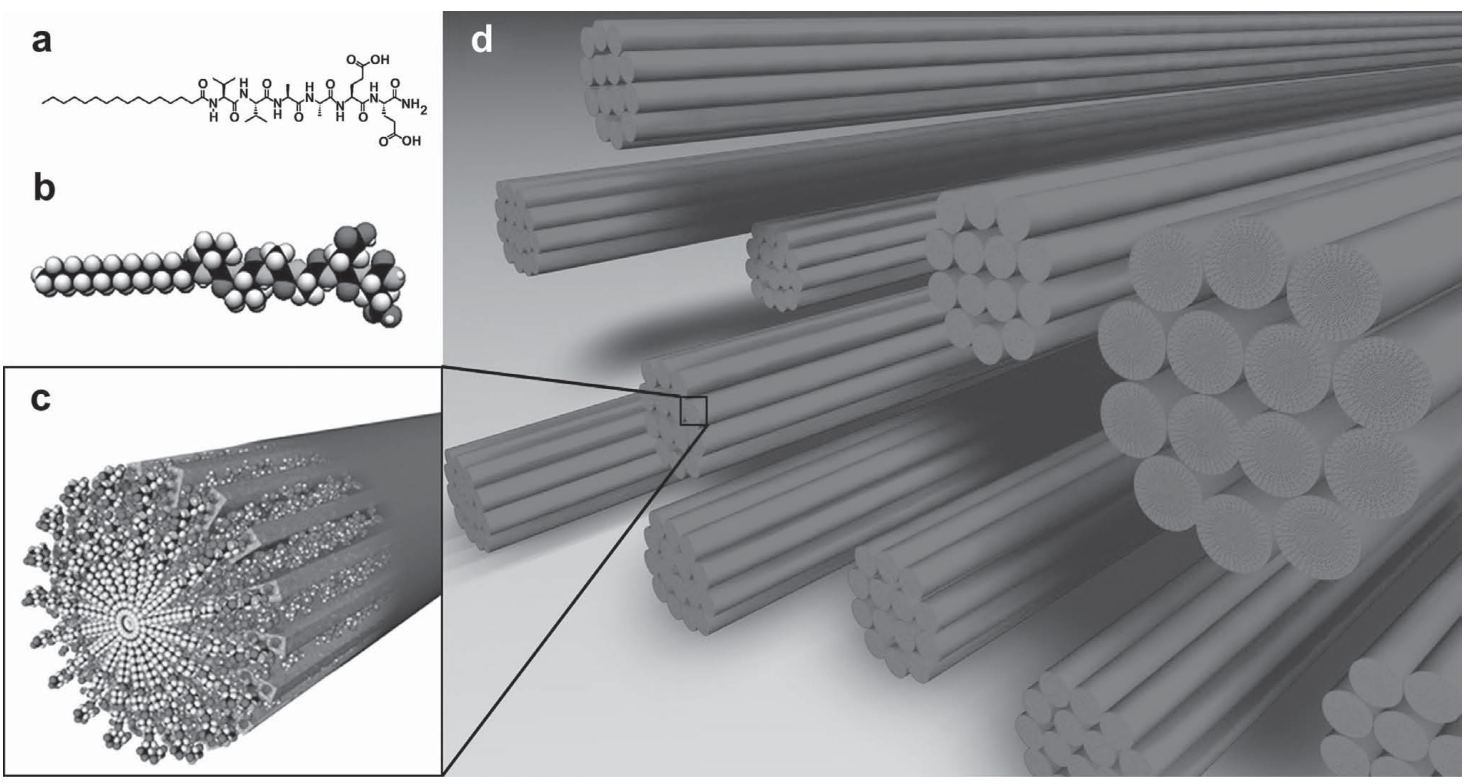

Figure 11. a) Molecular structure of the Palmitoyl-VVAAEE-Am) PA; b) Representative image of the PA molecule, c) Self-assembly of PA molecules forming nanofiber, d) Representative image of nanofiber bundles. Reproduced with permission. ${ }^{[78]}$ Copyright 2011, Elsevier.

imitate the interaction of laminin with heparin sulphate proteoglycan (HSPG). ${ }^{[120]}$ Mammadov et al. demonstrated that the combination in question could cooperatively induce neurite outgrowth of PC-12 cells when compared with laminin-derived scaffold alone. In addition, this system was shown to be effective in bypassing the inhibitory action of CSPGs (chondroitin sulphate proteoglycans) on axonal growth (Figure 14).

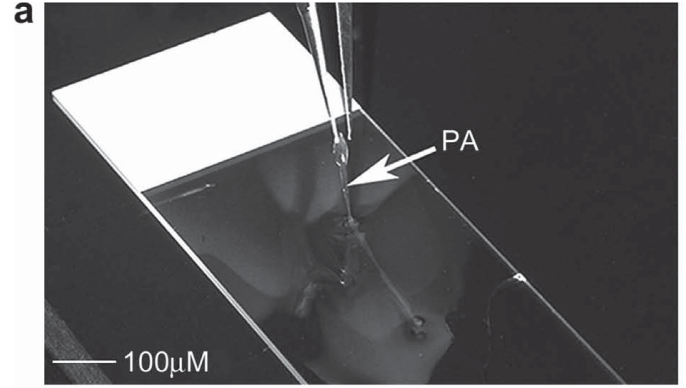

Control

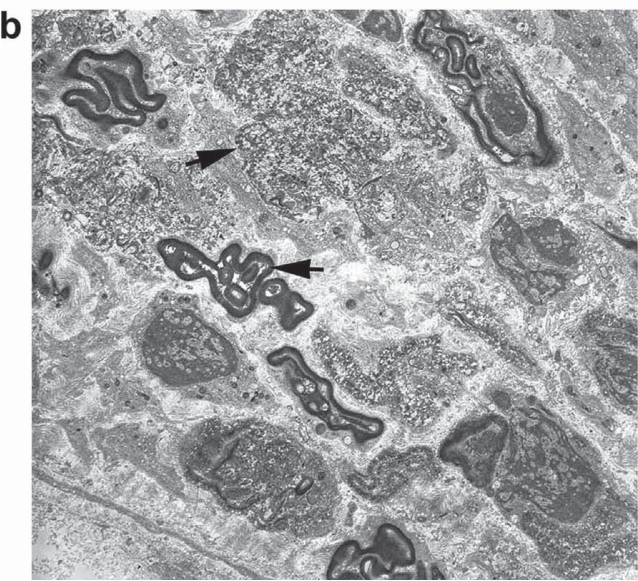

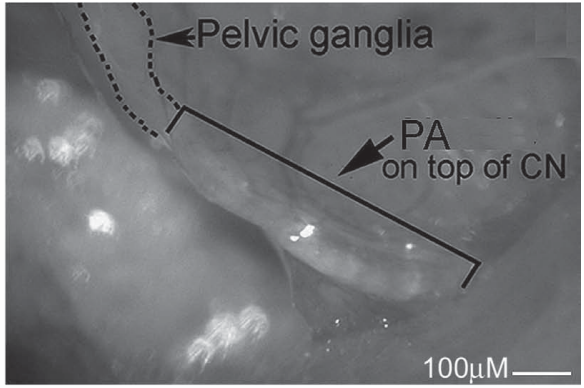

SHH protein

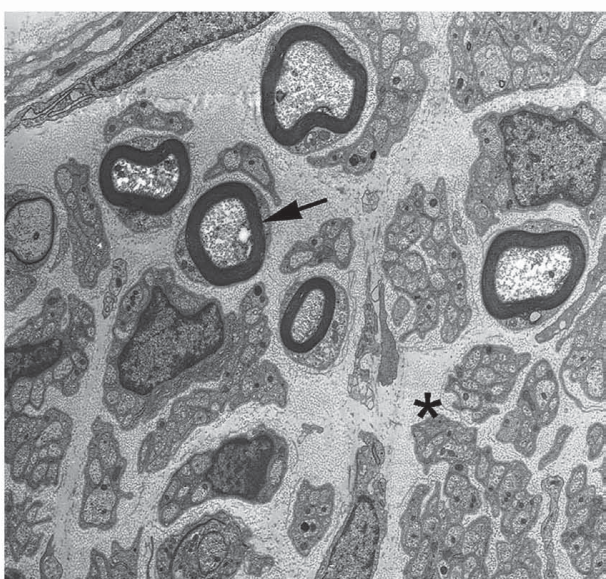

Figure 12. a) Linear PA formation and in vivo application of PA b) Bilateral CN crush in EM of Sprague-Dawley rats: treated with BSA-PA (control) or SHH-PA for 4 weeks. Intact myelinated fibers in the SHH treated $\mathrm{CN}$ and visible axonal sprouts in non-myelinated fibers (asterisk). 30 000 $\mathrm{x}$ and 44 000x. Reproduced with permission. ${ }^{[78]}$ Copyright 2011, Elsevier. 

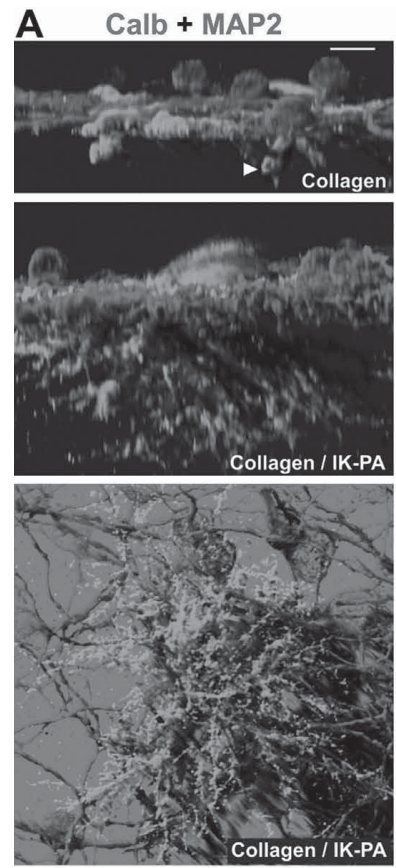
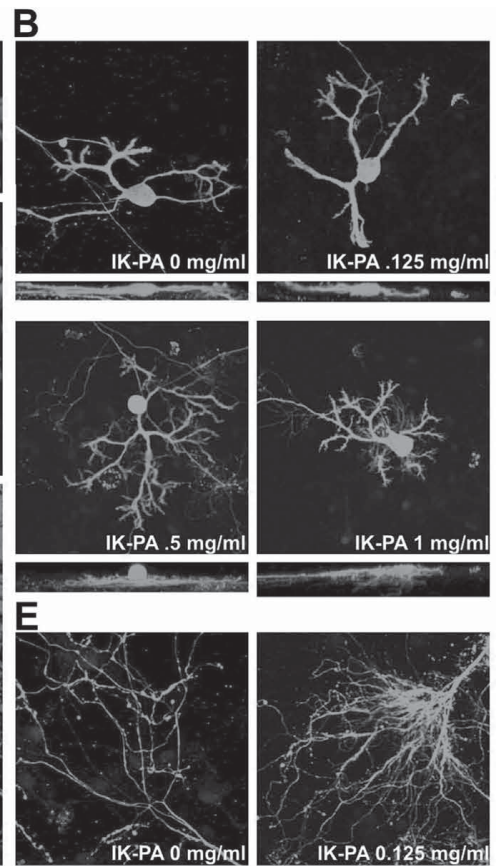
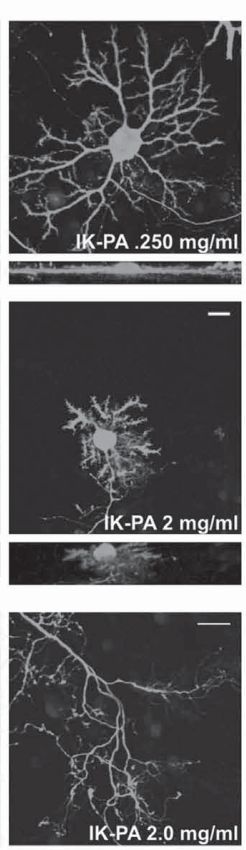

C
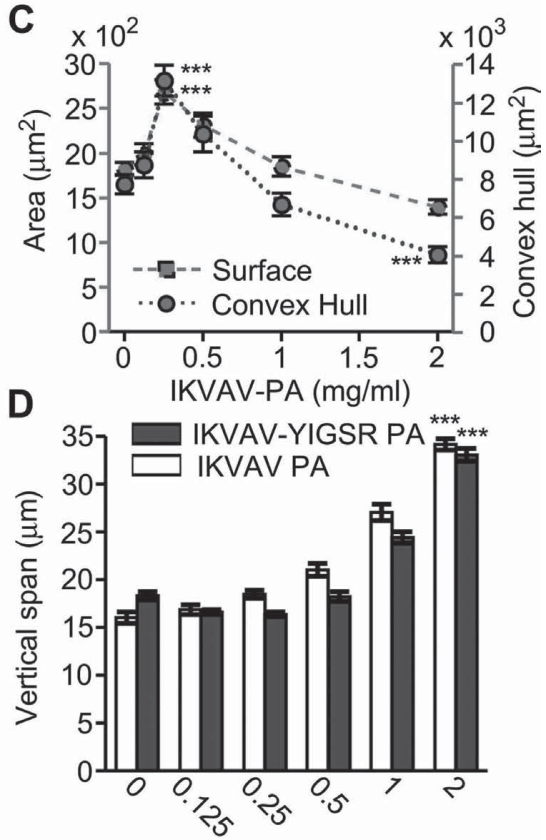

PA concentration $(\mathrm{mg} / \mathrm{ml})$

Figure 13. Results of matrix composition on Purkinje cell (PC) morphology. A) Simulated fluorescence process images of PCs (Calbindin, green), cultured on either collagen (upper, side view) or collagen/IKVAV-PA hybrid matrix (middle, side view; lower, bottom view). The arrowhead indicates the random short invasion of PC dendrite into the collagen substrate. Dendrite dispersal of non-PC cerebellar neurons is shown in red (Scale-10 $\mu \mathrm{m})$ (MAP2.). B) Image pairs show the top view and side view of representative PC morphologies seen on hybrid matrices (Scale $20 \mu \mathrm{m}$ ). C) Plot of projected area and convex hull of PC surface dendrites against IKVAV-PA concentration. D) Plot of the PC vertical spans against different PA concentrations. E) Morphologies of PC axon terminals for different PA concentrations (Scale $20 \mu \mathrm{m}$ ). Reproduced with permission. ${ }^{[76]}$ Copyright 2012, Elsevier.

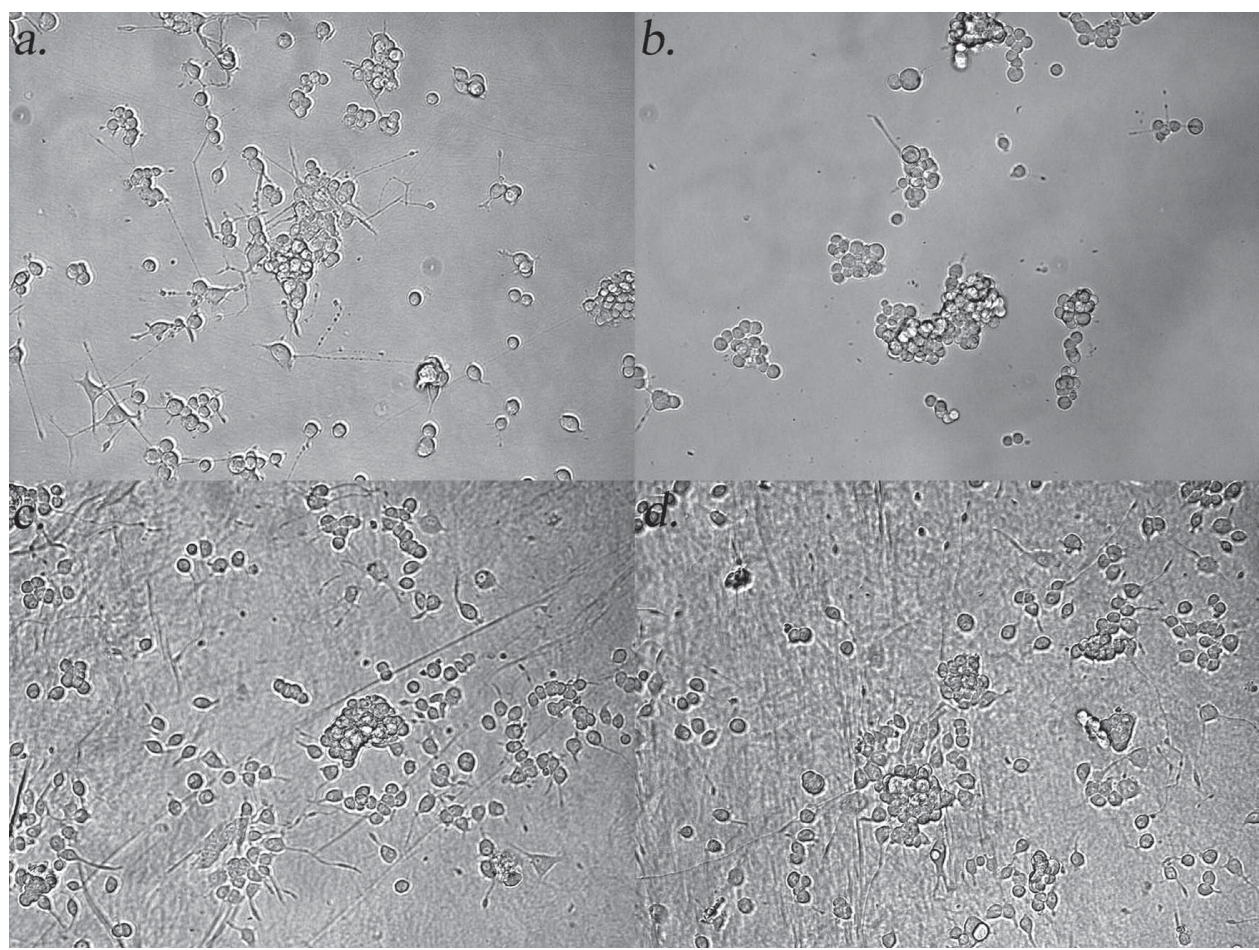

Figure 14. Optical microscope images of PC-12 cells bypass CSPG inhibition when cultured on PA scaffolds. Inhibition of neurite outgrowth of PC-12 cells on a) collagen alone surfaces b) CSPG mixed collagen coated surfaces. Successful extension of neurites on both d) CSPG added and c) CSPC IKVAV-PA/HSM-PA scaffolds. Reproduced with permission. ${ }^{[120]}$ Copyright 2012, Elsevier. 
Adult Chondrocyte
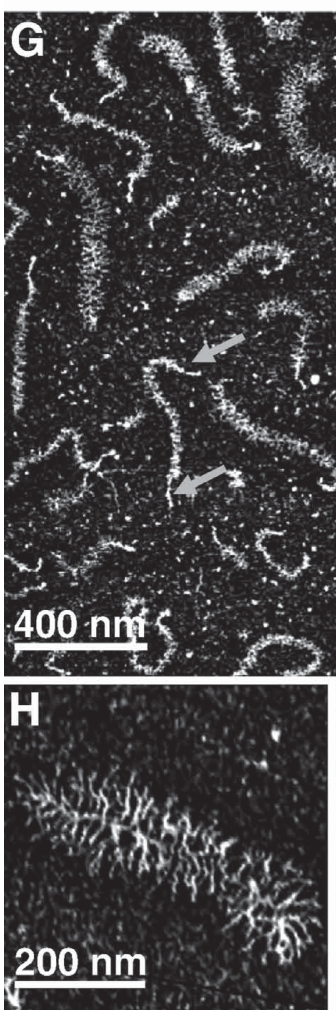

Adult BMSC

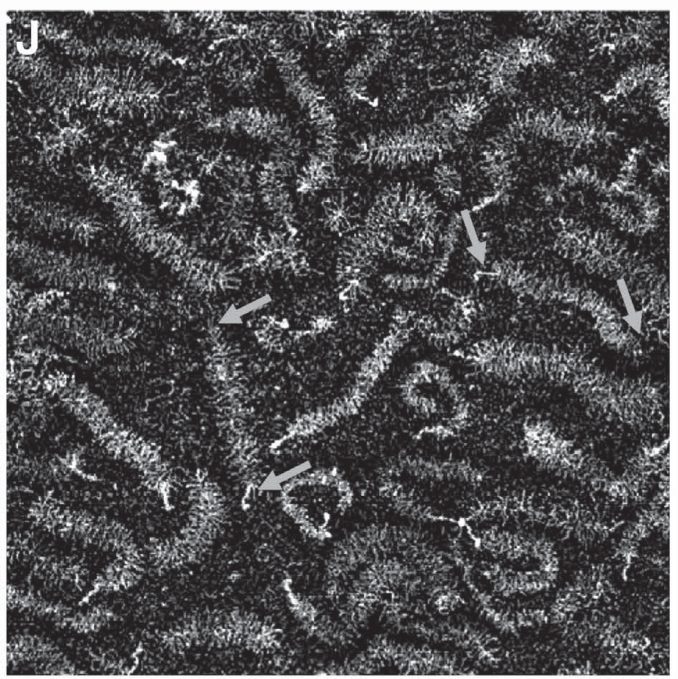

$0.60 \mathrm{~nm}$

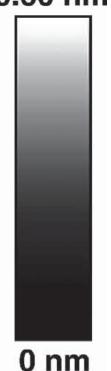

Figure 15. AFM images of aggrecan molecules of $\mathrm{G}-\mathrm{I}$ ) adult chondrocytes and $\mathrm{J}-\mathrm{L}$ ) BMSC. The arrows indicate the ends of full length aggrecan molecules. Reproduced with permission. ${ }^{[121]}$ Copyright 2010, Elsevier.

\subsection{Cartilage Regeneration with Peptide Nanofibers}

Despite rapid advances in other aspects of tissue engineering, the regeneration of damaged cartilage tissue remains as a challenge. Cartilage tissue engineering is primarily constrained by the low natural regenerative capacity of this tissue, which stems from its aneural, avascular, and alymphatic nature, as well as its limited cell supplies. As such, a great majority of the scaffolds designed for cartilage regeneration have been dissatisfactory, and mimicking natural ECM is now one of the crucial goals of cartilage tissue engineering in order to eliminate the limitations imposed by the present issues. As self-assembled PAs are strong ECM-mimetic material candidates, much research has been performed regarding their potential use in cartilage regeneration. In one such study, the peptide KLD-12 (AcN-KLDLKLDLKLDL-NH ${ }_{2}$ ) was used as a self-assembled peptide hydrogel for encapsulation of chondrocytes in a 3D environment, and was demonstrated to be comparable to other cartilage ECM-derived scaffolds for the retention of chondrocyte morphology. ${ }^{[69]}$ In another study, the same peptide (KLD12) was also reported to promote the chondrogenesis of bone marrow-derived mesenchymal stem cells (BMSCs). As clearly demonstrated in AFM images, hydrogel-encapsulated BMSCs expressed aggrecans (one of the important cartilage ECM compounds) with visibly larger average core-protein lengths than chondrocytes (Figure 15). ${ }^{[121]}$

The effect of PA nanofibers bound to a growth factor (TGF $\beta 1$ ) on the chondrogenic differentiation of BMSCs was investigated, and it was demonstrated that this scaffold could induce cell proliferation, differentiation, and the production of cartilage-like ECM. ${ }^{[122]}$ Shah et al. reported a PA bearing a high density of a transforming growth factor $\beta$-1TGF $\beta-1$ ) epitope and demonstrated its ability to enhance the viability and differentiation of MSCs to chondrocytes in vitro, as well as supporting regeneration of hyaline-like cartilage tissue in vivo. ${ }^{[85]}$ Liu et al. have utilized a complex of a coalesced polymer, polyethylene glycol, and a collagen mimetic PA bearing the GFOGER sequence flanked by GPO repeats. Their results suggest that the integrated system in question contributed significantly to the differentiation of hMSCs (human mesenchymal stem cells) into chondrocytes and augmented cartilage specific ECM production, in stark contrast to the polymer itself. ${ }^{[123]}$ Recently, we also showed that glycosaminoglycan (GAG) mimetic PAs are highly promising for inducing chondrogenesis in vitro. ${ }^{[124]}$ In particular, we have demonstrated that the cooperative effects of different molecules present in the natural ECM of chondrocytes may greatly assist in chondrogenic differentiation (Figure 16).

\subsection{Angiogenesis}

Angiogenesis is the process of new blood vessel generation and plays an important role for normal functioning of tissues. ${ }^{[125]}$ A fine balance between angiogenesis inducing and inhibiting factors regulates this process under normal conditions. This 
a.

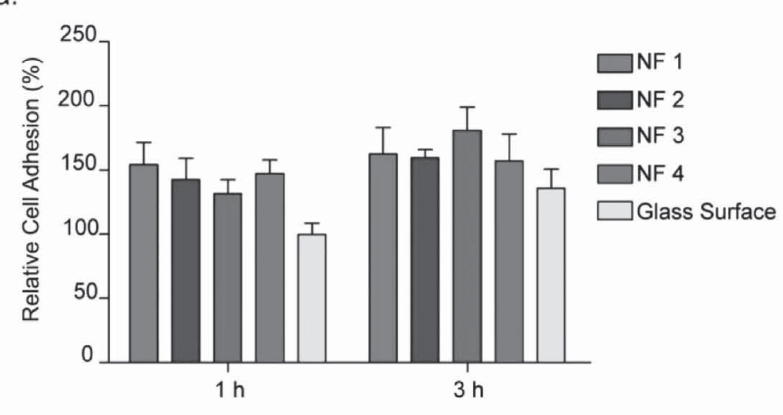

j.

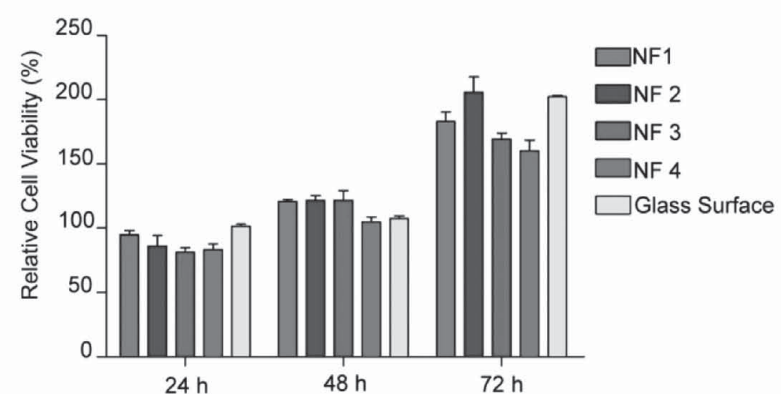

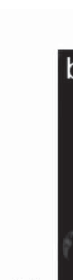
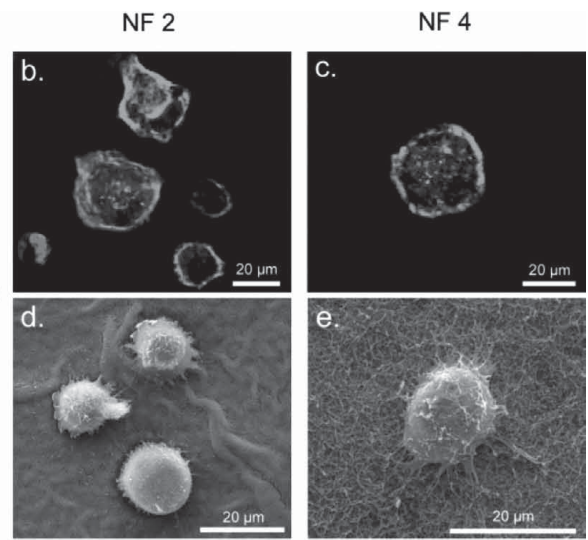

$48 \mathrm{~h}$
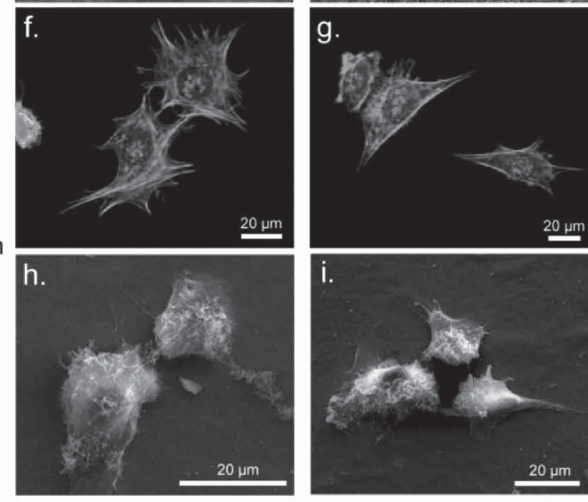

Figure 16. a) Cell adhesion and j) cell viability bar graphs. b-i) Cellular response to peptide amphiphiles shown with confocal and EM imagings. Reproduced with permission. ${ }^{[124]}$ Copyright 2013, American Chemical Society.

balance, however, is compromised in pathological conditions, creating fluctuations in blood vessel formation rates. As the regeneration of many tissues depends on the availability of healthy blood vessels, angiogenesis is also important in the process of wound healing, which renders it a crucial process in regenerative medicine.

Vascular endothelial growth factor (VEGF) is a major regulator of angiogenesis, and its effects are mediated by receptor tyrosine kinases VEGFR1 and VEGFR2. In addition, many other molecules, such as FGF, bFGF, HGF, angiogenin, transforming growth factor (TGF)- $\alpha$, TGF- $\beta$, and tumor necrosis factor- $\alpha$, are implicated to have roles in angiogenesis. ${ }^{[26]}$ Proper functioning of these growth factors is moderated by binding to ECM glycosaminoglycans: HSPGs bind to growth factors and regulate the signaling pathways that promote or inhibit angiogenesis. ${ }^{[127,128]}$

Malkar et al. have reported the effect of PA mixtures on endothelial cell behavior, using films of the angiogenesis-inducing sequence SPARC (secreted protein, acidic, cysteine-rich). SPARC-PA was found to promote cell adhesion and spreading to a greater extent when combined with $\mathrm{C}_{10}-\left[\alpha 1\right.$ (I)496-507], an integrin binding PA, and $\mathrm{C}_{10}$ carbon chain, than it was alone. ${ }^{[129]}$ In another study, angiogenic effect of heparin-binding peptide amphiphile (HBPA) hydrogels were evaluated in rat cornea. These nanostructures were found to promote maximal neovascularization response when combined with growth factors, compared to collagen gels with or without growth factors. ${ }^{[130]}$
In vivo reaction to HBPA nanofiber gel networks and the effect of heparin on this reaction was examined by Ghanaati et al. A heparin-binding PA and a fluorescein-conjugated PA were implanted subcutaneously to female CD-1 mice. Both static and dynamic analyses were performed to evaluate the in vivo biocompatibility of this angiogenic peptide, which was found to be excellent: The gels could persist in the tissue for up to $30 \mathrm{~d}$, and de novo vascularized connective tissue was observed following their biodegradation. ${ }^{[131]}$

Since VEGF is an important stimulator of angiogenesis, PA nanostructures were also designed to display a sequence that imitates VEGF for ischemic tissue repair. ${ }^{[65]}$ The sequence in question was KLTWQELYQLKYKGI-NH $\mathrm{N}_{2}$ and it was shown to specifically activate VEGF receptors in vitro, in addition to inducing angiogenesis in vivo. Angiogenic activity of this peptide was examined by chicken chorioallantoic membrane (CAM) assay, and the density of blood vessels was shown to increase significantly upon exposure to VEGF-PA (Figure 17).

A heparin-mimetic self-assembled PAs were investigated to induce angiogenesis in the absence of exogenous growth factors, and its in vivo efficacy was evaluated. ${ }^{[89]}$ In this study, the sulfonate group itself was not sufficient for optimal angiogenic outcome, and other chemical groups were required to induce the formation of capillary-like structures by endothelial cells. The heparin mimetic peptide was able to fulfill this function by presenting critical functional groups of heparin and regulating growth factor signaling, without requiring any other angiogenic supplement (Figure 18). Furthermore, heparin-mimetic PA gels 

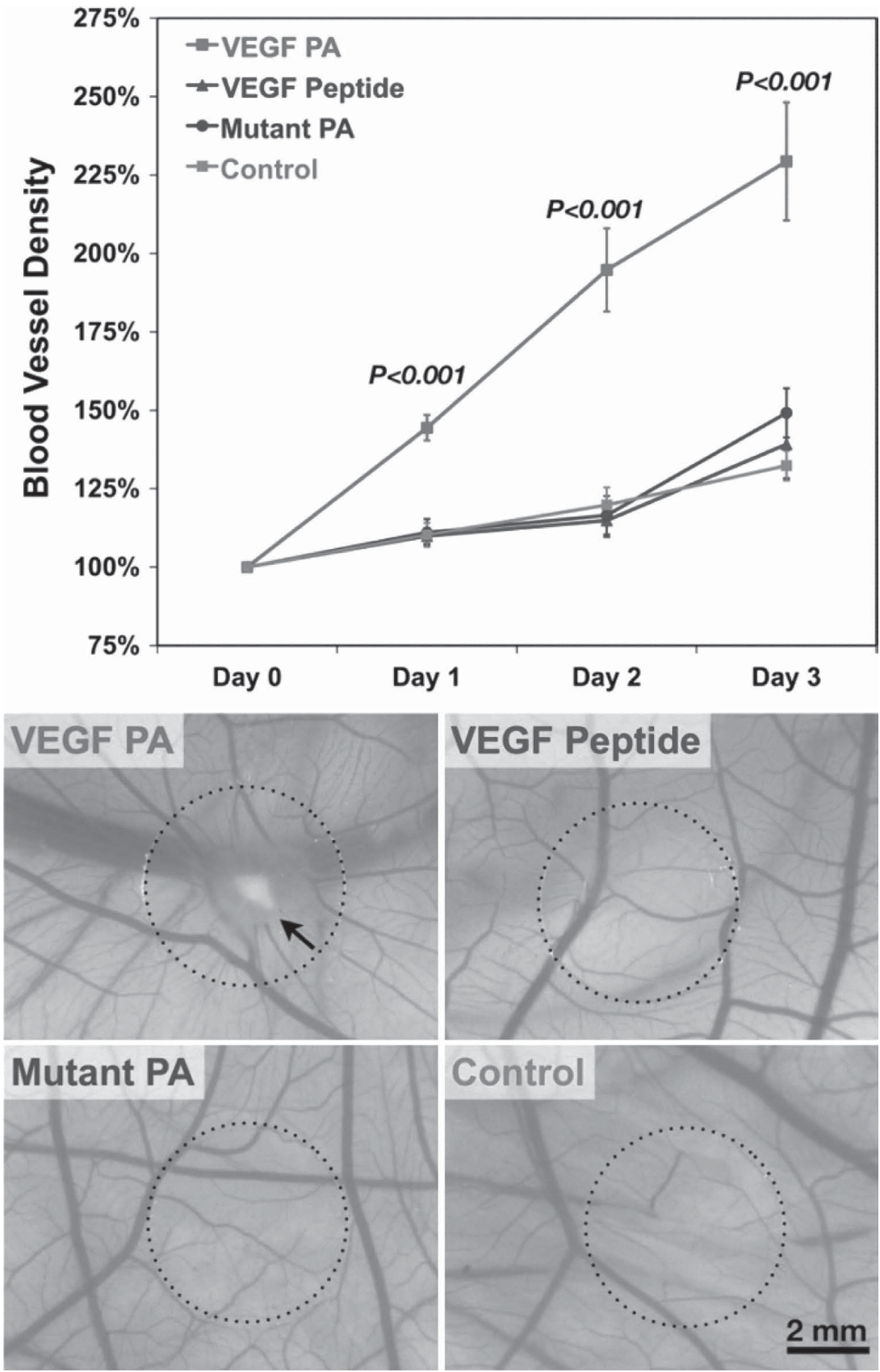

Figure 17. Quantified CAM assay results beginning on embryonic day $10(t=$ day 0$)$ and extending for $4 \mathrm{~d}$ along with representative images from day 3 for treatments of VEGF PA, VEGF peptide, mutant PA, and an untreated control. Reproduced with permission. ${ }^{[65]}$ Copyright 2011, National Academy of Science.

supplemented with a combination of VEGF and FGF-2 could induce neovascularization in rat cornea more efficiently compared to growth factor solution alone.

\subsection{Cardiovascular Regeneration}

Cardiovascular diseases are a major cause of death worldwide. Myocardial infarction, congestive heart failure, stroke, and other vascular diseases overall are responsible for $\approx 30 \%$ of all deaths. ${ }^{[132]}$ Cardiovascular diseases affect not only human health but also the economic stability around the world, as those disorders cause the affected individual leave the active workforce. ${ }^{[133]}$ Tissue engineering and regenerative medicine can offer faster recovery, and thus lessen the socioeconomic burden among patients suffering from cardiovascular diseases. ${ }^{[133]}$ Synthetic microenvironments resembling natural 3D structure of myocardial tissue is one of the crucial anticipation of cardiovascular tissue engineering. The use of self-assembled peptide nanofibers is a promising tool for cardiovascular regeneration as well. Davis et al. designed injectable peptide nanofibers (RADA16-II) for the assembly of intramyocardial cellular microenvironments and showed enhanced neovascularization through endothelial cell invasion to peptide microenvironment. Moreover, when they introduced smooth muscle cells into peptide microenvironment, they observed that they assembled arterioles. In this comprehensive research, Davis et al. also showed the presence myocyte progenitor cell population in the peptide microenvironment. Their results also demonstrated the superior benefit of self-assembled peptide nanofibers over Matrigel. In addition, they showed the spontaneous differentiation of embryonic stem cells into cardiac myocytes inside peptide microenvironment in vivo. ${ }^{[134]}$

In another study, Davis et al. designed a peptide nanofiber organization through a "biotin sandwich" method for the specific and controlled delivery of IGF-1 (insulinlike growth factor) into local myocardia microenvironment. IGF-1 bound nanofibers increased the cardiac specific marker expressions and protein synthesis in vitro. Moreover, IGF-1 bound peptide nanofibers reduced cardiomyocyte apoptosis, increased their survival and ameliorated the cell therapy in vivo after injury. ${ }^{[135]}$ Hsieh et al. showed the advantageous effect of usage of the selfassembled peptide nanofibers in myocardial protection through prolonged delivery of PDGF-BB when co-cultured with endothelial cells in vitro, and observed systolic function maintenance after myocardia infraction in vivo. ${ }^{[136]}$ Webber et al. developed bioactive peptide amphiphiles containing fibronectin-derived RGDS sequence, which is an important bioactive epitope for adhesion of bone marrow stromal cells and progenitor cells. They proposed the potential effect of these supportive nanofiber scaffolds on the ischemic tissue repair. They demonstrated increased biological adhesion, viability, and proliferation of these cells as well as maturation of endothelial cells in vitro. 

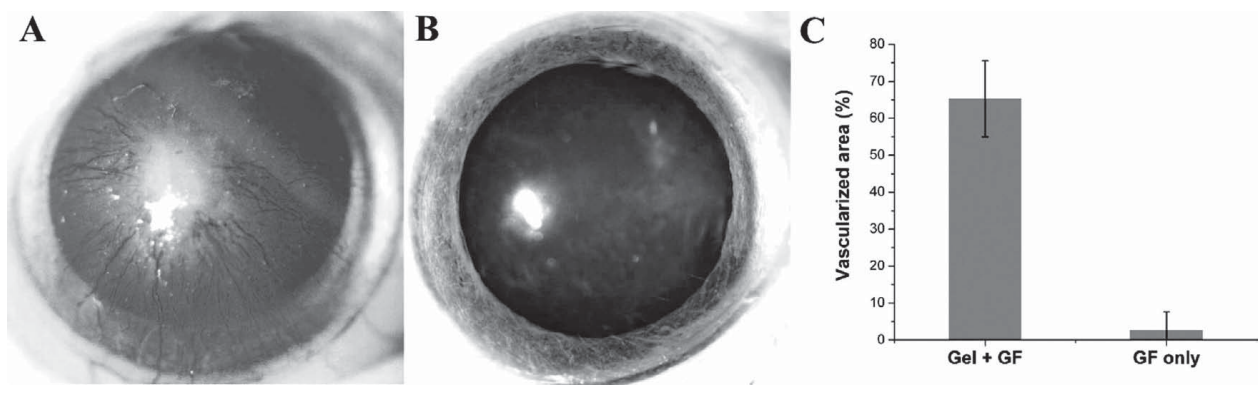

Figure 18. A) Chemical structure of heparin-mimetic PA. B) SEM image of nanofibrous network. C) 1 wt\% Heparin-mimetic PA gel injected with 10 ng of VEGF- and bFGF-induced vascularization in cornea. D) Application of growth factor solution without PA gel. E) Ratio of vascularized area to total area. Reproduced with permission. ${ }^{[89]}$ Copyright 2011, American Chemical Society.

Furthermore, they demonstrated the advanced effect of the RGDS nanofibers as supportive matrix for bone-marrow mononuclear cells in vivo. ${ }^{[72]}$

Another type of peptide nanofiber used in cardiovascular tissue repair is the heparin-binding peptide amphiphile. HBPA is a favorable PA system in myocardial regeneration, as it mimics the structure of natural heparin binding proteins and therefore increases the cellular recognition of heparin in the ECM. Webber et al. reported that paracrine factor delivered with HBPA had a nourishing effect on infracted myocardia in vivo. ${ }^{[137]}$

Metal-based stents are conventionally used for treatment of arterial diseases, and we have previously functionalized a stainless steel surface with peptide amphiphiles inspired by fibronectin (REDV-PA) and mussel foot adhesion proteins (DOPA-PA) to create stent coatings that mimic the natural endothelium ECM. In this study, surfaces functionalized with a combination of REDV-PA and DOPA-PA were shown to promote the selective adhesion of endothelial cells and inhibit the growth and differentiation of vascular smooth muscle cells, ${ }^{[102]}$ (Figure 19) which are promising results for the future clinical use of bioactive coatings in cardiovascular stents.

\section{Conclusions and Future Perspectives}

Self-assembling peptide molecules are versatile tools for generation of biomimetic materials with properties similar to that of the native tissue environment. In the repertoire of biomedical strategies, nearly all tissues are under exploration for regeneration with the help of these peptide scaffolds. In this Review, we focused on the published works investigating the effects of supramolecular peptide systems on the regeneration of specific tissue types. The use of peptide nanofiber systems increases with the promising results of different research groups. Despite the recent advances and developments, many challenges yet remain to be solved. One of these major challenges is the difficulty in understanding the mechanisms underlying cell response. Enhanced knowledge on these mechanisms and complex signaling pathways will enable generation of more defined synthetic platforms to improve the currently used biomaterials. Controlling the compositional aspects of the natural microenvironment and regulating the timing of cellular processes through these scaffolds are crucial; however, there are still many unknown proteins and factors modulating the time and amplitude of the changes occurring in the cells. In this respect, developments in proteomics can ease the understanding of functional domains of these tissue-specific proteins and factors. It may improve the strategies to generate more advanced peptide scaffolds with new sequences and conformations. Through these improvements in the peptide design, the complex hierarchical structures of tissues in organized 3D matrices can be mimicked, so that cells can receive all the necessary signals as if they were coming from a native matrix. It is also important to precisely control and manipulate the responses of the peptide systems upon environmental stimuli including chemical, mechanical, magnetic and electrical signals in order to fabricate stimuli-responsive and tissue-specific scaffolds. To accomplish these controls, employing new characterization methods including TEM, AFM, spectroscopy, and so forth, and computational approaches are required. Furthermore, accurate simulations as well as visualization of the materials both in vitro and in vivo are essential. Advances in the modeling programs for the precise simulations of peptide systems can provide visualization of the synthetically designed network at the molecular and structural levels. Indeed, this can overcome one of the most challenging problems of mimicking complex organization of tissues. For
Figure 19. Viability and proliferation of HUVEC and A7r5 smooth muscle cells on stainless steel surfaces coated with REDV-PA/Dopa-PA, E-PA/Dopa-PA, and on bare steel surface. Reproduced with permission. ${ }^{[102]}$ Copyright 2011, Elsevier.
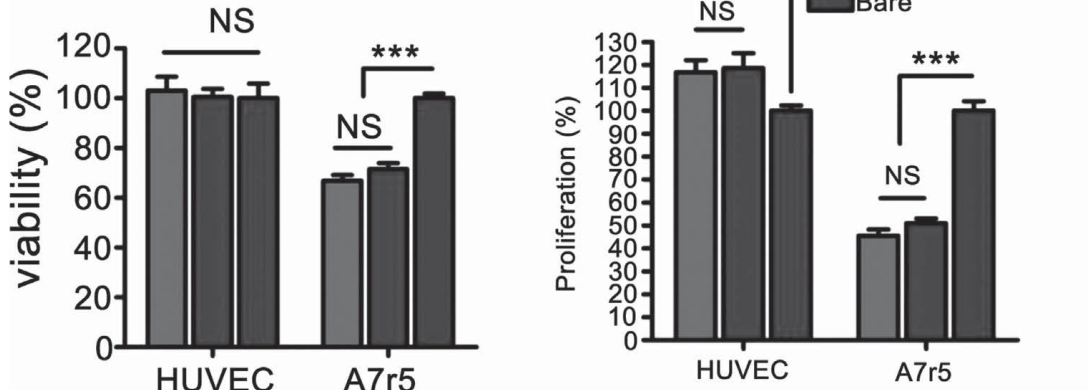

Adv. Healthcare Mater. 2014, 3, 1357-1376

(C) 2014 WILEY-VCH Verlag GmbH \& Co. KGaA, Weinheim 
example, extrapolating the responses of peptide nanofibers and the responses of cells (changes in signaling pathways resulting in regulation of cell growth, proliferation, differentiation, and migration towards desired locations) upon interaction with growth factors, cell receptors, enzymes, and other macromolecules can be achieved. Simulation and visualization of these systems can also puzzle out the problems associated with the unavailability of the bioactive sites on the scaffolds due to steric hindrance and unspecific interactions. As a result, superior design of biomaterials with enhanced bioactivity can be achieved.

Overall, the integration of advanced characterization, simulation, and visualization methods with the genomic and proteomic studies can overcome the current limitations in this field. Accordingly, spatiotemporal dynamic microenvironments with more sophisticated, advanced and more manageable peptide scaffolds can be constructed. In addition, optimization in the design and synthesis of peptides and their conjugates can accelerate the production of large-scale and ready-to-use biomaterials. Custom-made design of these biomaterials can further improve the clinical uses and the fabrication of patient-specific tissue constructs. Hence, challenges of this highly active field of research, at the same time provides opportunities for future progress and development of efficient biomaterials in terms of successful repair and regeneration of the damaged tissues.

\section{Acknowledgements}

E.A. and I.C.G. contributed equally to this work. I.C.G. and E.A. are supported by TUBITAK-BIDEB 2210 Ph.D. fellowship. M.O.G. and A.B.T. acknowledge support from the Turkish Academy of Sciences Distinguished Young Scientist Award (TUBA-GEBIP) and TUBITAK (112T042, 111M410, 111M710), A.B.T. acknowledges support form Loreál Young Women Investigator Award. Authors thank to A. D. Ozkan, Y. Tumtas, and O. Yasa for their fruitful discussions.

Received: August 29, 2013

Revised: November 19, 2013

Published online: February 25, 2014

[1] B. V. Slaughter, S. S. Khurshid, O. Z. Fisher, A. Khademhosseini, N. A. Peppas, Adv. Mater. 2009, 21, 3307

[2] C. Frantz, K. M. Stewart, V. M. Weaver, J. Cell Sci. 2010, 123, 4195.

[3] A. de Mel, A. M. Seifalian, M. A. Birchall, Macromol. Biosci. 2012, 12,1010

[4] R. A. Gittens, T. McLachlan, R. Olivares-Navarrete, Y. Cai, S. Berner, R. Tannenbaum, Z. Schwartz, K. H. Sandhage, B. D. Boyan, Biomaterials 2011, 32, 3395.

[5] H. G. Cui, M. J. Webber, S. I. Stupp, Biopolymers 2010, 94, 1.

[6] F. Grinnell, B. Geiger, Exp. Cell Res. 1986, 162, 449.

[7] K. Anselme, Biomaterials 2000, 21, 667.

[8] R. W. Sands, D. J. Mooney, Curr. Opin. Biotechnol. 2007, 18, 448.

[9] L. Ponsonnet, K. Reybier, N. Jaffrezic, V. Comte, C. Lagneau, M. Lissac, C. Martelet, Mater. Sci. Eng., C: Biomimetic Supramol. Syst. 2003, 23, 551.

[10] N. Donos, S. Hamlet, N. P. Lang, G. E. Salvi, G. Huynh-Ba, D. D. Bosshardt, S. Ivanovski, Clin. Oral. Implan. Res. 2011, 22, 365.

[11] P. B. Vanwachem, A. H. Hogt, T. Beugeling, J. Feijen, A. Bantjes, J. P. Detmers, W. G. Vanaken, Biomaterials 1987, 8, 323.
[12] N. J. Hallab, K. J. Bundy, K. Oconnor, R. Clark, R. L. Moses, J. Long-Term Effects Med. Implants 1995, 5, 209.

[13] J. R. Woodard, A. J. Hilldore, S. K. Lan, C. J. Park, A. W. Morgan, J. A. C. Eurell, S. G. Clark, M. B. Wheeler, R. D. Jamison, A. J. W. Johnson, Biomaterials 2007, 28, 45.

[14] C. A. Squier, P. Collins, J. Periodontal Res. 1981, 16, 434.

[15] I. Milinkovic, R. Rudolf, K. T. Raic, Z. Aleksic, V. Lazic, A. Todorovic, D. Stamenkovic, Mater. Tehnol. 2012, 46, 251.

[16] J. Y. Lim, H. J. Donahue, Tissue Eng. 2007, 13, 1879.

[17] R. G. Flemming, C. J. Murphy, G. A. Abrams, S. L. Goodman, P. F. Nealey, Biomaterials 1999, 20, 573.

[18] T. Yeung, P. C. Georges, L. A. Flanagan, B. Marg, M. Ortiz, M. Funaki, N. Zahir, W. Y. Ming, V. Weaver, P. A. Janmey, Cell Motil. Cytoskeleton 2005, 60, 24.

[19] A. J. Engler, S. Sen, H. L. Sweeney, D. E. Discher, Cell 2006, 126, 677.

[20] A. Engler, L. Bacakova, C. Newman, A. Hategan, M. Griffin, D. Discher, Biophys. J. 2004, 86, 617.

[21] M. O. Guler, S. Soukasene, J. F. Hulvat, S. I. Stupp, Nano Lett. 2005, 5, 249.

[22] D. S. W. Benoit, K. S. Anseth, Biomaterials 2005, 26, 5209.

[23] J. Wang, P. Layrolle, M. Stigter, K. de Groot, Biomaterials 2004, 25, 583.

[24] N. A. Peppas, Y. Huang, M. Torres-Lugo, J. H. Ward, J. Zhang, Annu. Rev. Biomed. Eng. 2000, 2, 9.

[25] P. Habibovic, T. M. Sees, M. A. van den Doel, C. A. van Blitterswijk, K. de Groot, J. Biomed. Mater. Res., Part A 2006, 77A, 747.

[26] T. H. Barker, Biomaterials 2011, 32, 4211.

[27] M. Z. Atassi, T. Manshouri, Proc. Natl. Acad. Sci. U. S. A. 1993, $90,8282$.

[28] J. F. Shi, Y. A. Gao, Z. M. Yang, B. Xu, Beilstein J. Org. Chem. 2011, 7, 167.

[29] Z. M. Yang, H. W. Gu, D. G. Fu, P. Gao, J. K. Lam, B. Xu, Adv. Mater. 2004, 16, 1440

[30] Z. M. Yang, H. W. Gu, Y. Zhang, L. Wang, B. Xu, Chem. Commun. 2004, 208.

[31] D. M. Ryan, S. B. Anderson, F. T. Senguen, R. E. Youngman, B. L. Nilsson, Soft Matter 2010, 6, 475.

[32] S. Sutton, N. L. Campbell, A. I. Cooper, M. Kirkland, W. J. Frith, D. J. Adams, Langmuir 2009, 25, 10285.

[33] D. M. Ryan, S. B. Anderson, B. L. Nilsson, Soft Matter 2010, 6, 3220 .

[34] M. Reches, E. Gazit, Science 2003, 300, 625.

[35] R. Orbach, L. Adler-Abramovich, S. Zigerson, I. Mironi-Harpaz, D. Seliktar, E. Gazit, Biomacromolecules 2009, 10, 2646.

[36] C. J. Bowerman, W. Liyanage, A. J. Federation, B. L. Nilsson, Biomacromolecules 2011, 12, 2735.

[37] G. Cinar, H. Ceylan, M. Urel, T. S. Erkal, E. Deniz Tekin, A. B. Tekinay, A. Dâna, M. O. Guler, Biomacromolecules 2012, 13, 3377.

[38] A. Mahler, M. Reches, M. Rechter, S. Cohen, E. Gazit, Adv. Mater. 2006, 18, 1365.

[39] D. J. Pochan, J. P. Schneider, J. Kretsinger, B. Ozbas, K. Rajagopal, L. Haines, J. Am. Chem. Soc. 2003, 125, 11802.

[40] L. Haines-Butterick, K. Rajagopal, M. Branco, D. Salick, R. Rughani, M. Pilarz, M. S. Lamm, D. J. Pochan, J. P. Schneider, Proc. Natl. Acad. Sci. U. S. A. 2007, 104, 7791.

[41] W. H. Landschulz, P. F. Johnson, S. L. McKnight, Science 1988, 240, 1759.

[42] S. M. Yu, Y. Li, D. Kim, Soft Matter 2011, 7, 7927.

[43] L. E. R. O'Leary, J. A. Fallas, E. L. Bakota, M. K. Kang, J. D. Hartgerink, Nat. Chem. 2011, 3, 821.

[44] S. Zhang, D. M. Marini, W. Hwang, S. Santoso, Curr. Opin. Chem. Biol. 2002, 6, 865.

[45] S. Toksoz, M. O. Guler, Nano Today 2009, 4, 458. 
[46] J. D. Hartgerink, E. Beniash, S. I. Stupp, Proc. Natl. Acad. Sci. U. S. A. 2002, 99, 5133.

[47] J. B. Matson, S. I. Stupp, Chem. Commun. 2012, 48, 26

[48] J. B. Matson, R. H. Zha, S. I. Stupp, Curr. Opin. Solid State Mater. Sci. 2011, 15, 225.

[49] M. J. Webber, J. A. Kessler, S. I. Stupp, J. Intern. Med. 2010, 267, 71.

[50] H. Hosseinkhani, M. Hosseinkhani, H. Kobayashi, Biomed. Mater. 2006, 1,8.

[51] F. Versluis, H. R. Marsden, A. Kros, Chem. Soc. Rev. 2010, 39 , 3434.

[52] X. Zhao, F. Pan, H. Xu, M. Yaseen, H. Shan, C. A. Hauser, S. Zhang, J. R. Lu, Chem. Soc. Rev. 2010, 39, 3480.

[53] D. W. P. M. Lowik, J. C. M. van Hest, Chem. Soc. Rev. 2004, 33, 234.

[54] S. Toksoz, H. Acar, M. O. Guler, Soft Matter 2010, 6, 5839.

[55] N. Stephanopoulos, J. H. Ortony, S. I. Stupp, Acta Mater. 2013 61, 912.

[56] S. P. Zustiak, Y. Wei, J. B. Leach, Tissue Eng., Part B 2013, 19, 160.

[57] R. Mammadov, A. B. Tekinay, A. Dana, M. O. Guler, Micron 2012, $43,69$.

[58] H. Cui, M. J. Webber, S. I. Stupp, Pept. Sci. 2010, 94, 1.

[59] E. Kokkoli, A. Mardilovich, A. Wedekind, E. L. Rexeisen, A. Garg, J. A. Craig, Soft Matter 2006, 2, 1015.

[60] S. G. Zhang, D. M. Marini, W. Hwang, S. Santoso, Curr. Opin. Chem. Biol. 2002, 6, 865

[61] M. J. Webber, J. A. Kessler, S. I. Stupp, J. Intern. Med. 2010, 267, 71.

[62] D. N. Woolfson, Z. N. Mahmoud, Chem. Soc. Rev. 2010, 39, 3464

[63] D. Sengupta, S. C. Heilshorn, Tissue Eng., Part B 2010, 16, 285.

[64] X. Liu, X. M. Wang, X. J. Wang, H. Ren, J. He, L. Qiao, F. Z. Cui, Acta Biomater. 2013, 9, 6798.

[65] M. J. Webber, J. Tongers, C. J. Newcomb, K. T. Marquardt, J. Bauersachs, D. W. Losordo, S. I. Stupp, Proc. Natl. Acad. Sci. U. S. A. 2011, 108, 13438.

[66] S. G. Zhang, C. Lockshin, R. Cook, A. Rich, Biopolymers 1994, 34, 663.

[67] S. G. Zhang, T. C. Holmes, C. M. Dipersio, R. O. Hynes, X. Su, A. Rich, Biomaterials 1995, 16, 1385.

[68] T. C. Holmes, S. de Lacalle, X. Su, G. Liu, A. Rich, S. Zhang, Proc. Natl. Acad. Sci. U. S. A. 2000, 97, 6728.

[69] J. Kisiday, M. Jin, B. Kurz, H. Hung, C. Semino, S. Zhang, A. J. Grodzinsky, Proc. Natl. Acad. Sci. U. S. A. 2002, 99, 9996.

[70] H. Yokoi, T. Kinoshita, S. Zhang, Proc. Natl. Acad. Sci. U. S. A. 2005, 102, 8414.

[71] F. Gelain, D. Bottai, A. Vescovi, S. Zhang, PLoS One 2006, 1, e119.

[72] M. J. Webber, J. Tongers, M. A. Renault, J. G. Roncalli, D. W. Losordo, S. I. Stupp, Acta Biomater. 2010, 6, 3.

[73] Z. Huang, C. J. Newcomb, Y. Zhou, Y. P. Lei, P. Bringas Jr., S. I. Stupp, M. L. Snead, Biomaterials 2013, 34, 3303.

[74] K. Tashiro, G. C. Sephel, B. Weeks, M. Sasaki, G. R. Martin, H. K. Kleinman, Y. Yamada, J. Biol. Chem. 1989, 264, 16174.

[75] V. M. Tysseling-Mattiace, V. Sahni, K. L. Niece, D. Birch C. Czeisler, M. G. Fehlings, S. I. Stupp, J. A. Kessler, J. Neurosci. 2008, 28, 3814.

[76] S. Sur, E. T. Pashuck, M. O. Guler, M. Ito, S. I. Stupp, T. Launey, Biomaterials 2012, 33, 545.

[77] Y. Iwamoto, M. Nomizu, Y. Yamada, Y. Ito, K. Tanaka, Y. Sugioka, Br. J. Cancer 1996, 73, 589 .

[78] N. L. Angeloni, C. W. Bond, Y. Tang, D. A. Harrington, S. Zhang, S. I. Stupp, K. E. McKenna, C. A. Podlasek, Biomaterials 2011, 32, 1091.

[79] J. C. Stendahl, D. B. Kaufman, S. I. Stupp, Cell Transplant. 2009, $18,1$.

[80] T. I. Kim, J. H. Jang, Y. M. Lee, I. C. Ryu, C. P. Chung, S. B. Han, S. M. Choi, Y. Ku, Biotechnol. Lett. 2002, 24, 2029.
[81] C. Frantz, K. M. Stewart, V. M. Weaver, J. Cell Sci. 2010, 123, 4195.

[82] A. M. Wojtowicz, A. Shekaran, M. E. Oest, K. M. Dupont, K. L. Templeman, D. W. Hutmacher, R. E. Guldberg, A. J. Garcia, Biomaterials 2010, 31, 2574.

[83] H. Cui, M. J. Webber, S. I. Stupp, Biopolymers 2010, 94, 1.

[84] J. M. Anderson, M. Kushwaha, A. Tambralli, S. L. Bellis, R. P. Camata, H. W. Jun, Biomacromolecules 2009, 10, 2935.

[85] R. N. Shah, N. A. Shah, M. M. Del Rosario Lim, C. Hsieh, G. Nuber, S. I. Stupp, Proc. Natl. Acad. Sci. U. S. A. 2010, 107, 3293.

[86] X. Wen, W. P. Cawthorn, O. A. MacDougald, S. I. Stupp M. L. Snead, Y. Zhou, Biomaterials 2011, 32, 6478.

[87] M. O. Guler, J. K. Pokorski, D. H. Appella, S. I. Stupp, Bioconjug. Chem. 2005, 16, 501.

[88] S. Soukasene, D. J. Toft, T. J. Moyer, H. Lu, H. K. Lee, S. M. Standley, V. L. Cryns, S. I. Stupp, ACS Nano 2011, 5, 9113.

[89] R. Mammadov, B. Mammadov, S. Toksoz, B. Aydin, R. Yagci, A. B. Tekinay, M. O. Guler, Biomacromolecules 2011, 12, 3508.

[90] M. Nelson, G. Balasundaram, T. J. Webster, Int. J. Nanomed. 2006 1,339

[91] M. J. Webber, J. B. Matson, V. K. Tamboli, S. I. Stupp, Biomaterials 2012, 33, 6823.

[92] J. B. Matson, M. J. Webber, V. K. Tamboli, B. Weber, S. I. Stupp, Soft Matter 2012, 8, 2689.

[93] S. Zhang, T. C. Holmes, C. M. DiPersio, R. O. Hynes, X. Su, A. Rich, Biomaterials 1995, 16, 1385.

[94] G. J. Meijer, J. D. de Bruijn, R. Koole, C. A. van Blitterswijk, PLoS Med. 2007, 4, 260

[95] H. Shin, S. Jo, A. G. Mikos, Biomaterials 2003, 24, 4353.

[96] E. H. J. Groeneveld, J. P. A. van den Bergh, P. Holzmann C. M. ten Bruggenkate, D. B. Tuinzing, E. H. Burger, J. Biomed. Mater. Res. 1999, 48, 393

[97] R. Pytela, M. D. Pierschbacher, S. Argraves, S. Suzuki, E. Ruoslahti, Methods Enzymol. 1987, 144, 475.

[98] D. A. Puleo, R. Bizios, Bone 1991, 12, 271.

[99] L. C. Palmer, C. J. Newcomb, S. R. Kaltz, E. D. Spoerke, S. I. Stupp, Chem. Rev. 2008, 108, 4754.

[100] J. D. Hartgerink, E. Beniash, S. I. Stupp, Science 2001, 294, 1684.

[101] Z. Huang, T. D. Sargeant, J. F. Hulvat, A. Mata, P. Bringas, C. Y. Koh, S. I. Stupp, M. L. Snead, J. Bone Miner. Res. 2008, 23 , 1995.

[102] H. Ceylan, A. B. Tekinay, M. O. Guler, Biomaterials 2011, 32, 8797

[103] H. Ceylan, S. Kocabey, A. B. Tekinay, M. O. Guler, Soft Matter 2012, 8, 3929.

[104] T. D. Sargeant, M. S. Rao, C. Y. Koh, S. I. Stupp, Biomaterials 2008 29, 1085.

[105] A. Mata, Y. B. Geng, K. J. Henrikson, C. Aparicio, S. R. Stock, R. L. Satcher, S. I. Stupp, Biomaterials 2010, 31, 6004.

[106] J. N. Luo, Y. W. Tong, ACS Nano 2011, 5, 7739.

[107] K. M. Hennessy, B. E. Pollot, W. C. Clem, M. C. Phipps, A. A. Sawyer, B. K. Culpepper, S. L. Bellis, Biomaterials 2009, 30, 1898.

[108] G. M. Harbers, K. E. Healy, J. Biomed. Mater. Res., Part A 2005 $75 \mathrm{~A}, 855$

[109] J. M. Anderson, J. B. Vines, J. L. Patterson, H. Chen, A. Javed H. W. Jun, Acta Biomater. 2011, 7, 675.

[110] K. C. Dee, T. T. Andersen, R. Bizios, J. Biomed. Mater. Res. 1998 $40,371$.

[111] J. Y. Lee, J. E. Choo, Y. S. Choi, J. S. Suh, S. J. Lee, C. P. Chung, Y. J. Park, Biomaterials 2009, 30, 3532.

[112] S. S. Lee, B. J. Huang, S. R. Kaltz, S. Sur, C. J. Newcomb, S. R. Stock, R. N. Shah, S. I. Stupp, Biomaterials 2013, 34, 452

[113] S. Y. Fu, T. Gordon, Mol. Neurobiol. 1997, 14, 67.

[114] W. Sulaiman, T. Gordon, Ochsner J. 2013, 13, 100. 
[115] T. C. Holmes, Trends Biotechnol. 2002, 20, 16.

[116] G. A. Silva, C. Czeisler, K. L. Niece, E. Beniash, D. A. Harrington, J. A. Kessler, S. I. Stupp, Science 2004, 303, 1352

[117] R. G. Ellis-Behnke, Y. X. Liang, S. W. You, D. K. Tay, S. Zhang, K. F. So, G. E. Schneider, Proc. Natl. Acad. Sci. U. S. A. 2006, 103, 5054

[118] Z. Zou, Q. Zheng, Y. Wu, X. Guo, S. Yang, J. Li, H. Pan, J. Biomed. Mater. Res., Part A 2010, 95, 1125.

[119] F. Taraballi, A. Natalello, M. Campione, O. Villa, S. M. Doglia, A. Paleari, F. Gelain, Front. Neuroeng. 2010, 3, 1.

[120] B. Mammadov, R. Mammadov, M. O. Guler, A. B. Tekinay, Acta Biomater. 2012, 8, 2077.

[121] P. W. Kopesky, H. Y. Lee, E. J. Vanderploeg, J. D. Kisiday, D. D. Frisbie, A. H. Plaas, C. Ortiz, A. J. Grodzinsky, Matrix Biol. 2010, 29, 427.

[122] P. W. Kopesky, E. J. Vanderploeg, J. D. Kisiday, D. D. Frisbie, J. D. Sandy, A. J. Grodzinsky, Tissue Eng., Part A 2011, 17, 83.

[123] S. Q. Liu, Q. Tian, J. L. Hedrick, J. H. Po Hui, P. L. Ee, Y. Y. Yang, Biomaterials 2010, 31, 7298

[124] S. Ustun, A. Tombuloglu, M. Kilinc, M. O. Guler, A. B. Tekinay, Biomacromolecules 2013, 14, 17.

[125] M. P. Lutolf, J. A. Hubbell, Nat. Biotechnol. 2005, 23, 47.

[126] N. Ferrara, H. P. Gerber, J. LeCouter, Nat. Med. 2003, 9, 669.

[127] J. Schlessinger, A. N. Plotnikov, O. A. Ibrahimi, A. V. Eliseenkova, B. K. Yeh, A. Yayon, R. J. Linhardt, M. Mohammadi, Mol. Cell 2000, 6, 743.

[128] W. J. Fairbrother, M. A. Champe, H. W. Christinger, B. A. Keyt, M. A. Starovasnik, Struct. Fold. Des. 1998, 6, 637.

[129] N. B. Malkar, J. L. Lauer-Fields, D. Juska, G. B. Fields, Biomacromolecules 2003, 4, 518.

[130] K. Rajangam, H. A. Behanna, M. J. Hui, X. Q. Han, J. F. Hulvat, J. W. Lomasney, S. I. Stupp, Nano Lett. 2006, 6, 2086.

[131] S. Ghanaati, M. J. Webber, R. E. Unger, C. Orth, J. F. Hulvat, S. E. Kiehna, M. Barbeck, A. Rasic, S. I. Stupp, C. J. Kirkpatrick, Biomaterials 2009, 30, 6202.

[132] V. L. Roger, A. S. Go, D. M. Lloyd-Jones, R. J. Adams, J. D. Berry, T. M. Brown, M. R. Carnethon, S. Dai, G. de Simone, E. S. Ford, C. S. Fox, H. J. Fullerton, C. Gillespie, K. J. Greenlund, S. M. Hailpern, J. A. Heit, P. M. Ho, V. J. Howard, B. M. Kissela, S. J. Kittner, D. T. Lackland, J. H. Lichtman, L. D. Lisabeth, D. M. Makuc, G. M. Marcus, A. Marelli, D. B. Matchar, M. M. McDermott, J. B. Meigs, C. S. Moy, D. Mozaffarian, M. E. Mussolino, G. Nichol, N. P. Paynter, W. D. Rosamond,
P. D. Sorlie, R. S. Stafford, T. N. Turan, M. B. Turner, N. D. Wong, J. Wylie-Rosett, Circulation 2011, 123, e18.

[133] J. G. Nemeno-Guanzon, S. Lee, J. R. Berg, Y. H. Jo, J. E. Yeo, B. M. Nam, Y. G. Koh, J. I. Lee, J. Biomed. Biotechnol. 2012, 2012, 956345.

[134] M. E. Davis, J. P. Motion, D. A. Narmoneva, T. Takahashi, D. Hakuno, R. D. Kamm, S. Zhang, R. T. Lee, Circulation 2005, 111, 442.

[135] M. E. Davis, P. C. Hsieh, T. Takahashi, Q. Song, S. Zhang, R. D. Kamm, A. J. Grodzinsky, P. Anversa, R. T. Lee, Proc. Natl. Acad. Sci. U. S. A. 2006, 103, 8155.

[136] P. C. H. Hsieh, M. E. Davis, J. Gannon, C. MacGillivray, R. T. Lee, J. Clin. Invest. 2006, 116, 237.

[137] M. J. Webber, X. Q. Han, S. N. P. Murthy, K. Rajangam, S. I. Stupp, J. W. Lomasney, J. Tissue Eng. Regen. Med. 2010, 4, 600.

[138] K. Rajangam, M. S. Arnold, M. A. Rocco, S. I. Stupp, Biomaterials 2008, 29, 3298.

[139] S. Aota, M. Nomizu, K. M. Yamada, J. Biol. Chem. 1994, 269, 24756.

[140] M. Standley, D. J. Toft, H. Cheng, S. Soukasene, J. Chen, S. M. Raja, V. Band, H. Band, V. L. Cryns, S. I. Stupp, Cancer Res. 2010, 70, 3020.

[141] J. Castillo-León, K. B. Andersen, Winnie E. Svendsen, in Biomater. Sci. Eng., (Ed: R. Pignatello), InTech, Rijeka, Crotia 2011, Ch.5.

[142] D. Chow, M. L. Nunalee, D. W. Lim, A. J. Simnick, A. Chilkoti, Mater. Sci. Eng., R. 2008, 62, 125.

[143] A. Aggeli, M. Bell, L. M. Carrick, C. W. G. Fishwick, R. Harding, P. J. Mawer, S. E. Radford, A. E. Strong, N. Boden, J. Am. Chem. Soc. 2003, 125, 9619.

[144] M. Reches, E. Gazit, Nat. Nanotechnol. 2006, 1, 195.

[145] J. Castillo-León, R. n. Rodriguez-Trujillo, S. Gauthier, A. C. ò. Jensen, W. E. Svendsen, Microelectron. Eng. 2011, 88, 1685

[146] J. Kopeček, J. Yang, Polym. Int. 2007, 56, 1078.

[147] J. Castillo, S. Tanzi, M. Dimaki, W. Svendsen, Electrophoresis 2008 , 29, 5026.

[148] T. Scheibel, R. Parthasarathy, G. Sawicki, X.-M. Lin, H. Jaeger, S. L. Lindquist, Proc. Natl. Acad. Sci. U. S. A. 2003, 100, 4527.

[149] D. T. Bong, T. D. Clark, J. R. Granja, M. R. Ghadiri, Angew. Chem., Int. Ed. 2001, 40, 988.

[150] C. H. Görbitz, Chem.-Eur. J. 2001, 7, 5153.

[151] K. B. Andersen, J. Castillo-Leon, M. Hedstrom, W. E. Svendsen, Nanoscale 2011, 3, 994 